\section{Abstract}

9 Different findings about suitable correlations to describe nanofluid viscosity can

\section{behavior}

\author{
Leyla Raeisian $^{1}$, Jan Rudolf Eggers ${ }^{1}$, Eckart Matthias Lange ${ }^{1 *}$, Torsten Mattke ${ }^{2}$, \\ Andreas Bode ${ }^{2}$, Stephan Kabelac ${ }^{1}$ \\ ${ }^{1}$ Institute of Thermodynamics, Leibniz University Hannover, Germany \\ ${ }^{2}$ BASF SE, Ludwigshafen, Germany \\ * Corresponding author: lange@ift.uni-hannover.de
}

of nanofluids is crucial when nanofluids are considered as heat carrier fluids.

2 Despite many publications however, no consensus about suitable correlations could be found in past years. Especially the impact of the shear rate on the viscosity is being discussed controversially. It is shown in this paper, that these different findings can be explained considering the theory for the rheology of suspensions. Any measurement of viscosity over shear rate only shows a section of the entire rheological behavior. Thus, experimental results of shear thinning, Newtonian behavior and shear thickening of nanofluids can all be a part of this overall range of possible shear rates. This hypothesis is validated based on viscosity data from literature and viscosity measurements over a wide range of shear rates for different nanofluids showing all three types of behavior.

Keywords: viscosity, shear rate, shear thinning, shear thickening, nanofluids

\section{Introduction}

Nanofluids, which are colloidal suspensions of metallic and/or nonmetallic nanoparticles with at least one dimension below $100 \mathrm{~nm}$ size dispersed in

\title{
On the controversy of nanofluid rheological
}


conventional base fluids, are known for their considerable impact on transport mechanisms which usually improve heat transfer abilities. In detail the increase of the heat transfer surface area due to suspended nanoparticles, interaction and collision between nanoparticles and higher thermal conductivity of nanoparticles are the mechanisms that cause the heat transfer increase in nanofluids [1]. In this regard, researchers see some potentials for heat transfer applications due to an increase of thermal conductivity of the nanofluid compared with the base fluid. Other applications for nanoparticles are e.g. treatment of cancer by hypothermia or power generation using nanofluids as solar volumetric absorbers, as the optical properties of liquids can be strongly influenced by nanoparticles [2-4].

Most of the publications have focused on the thermal conductivity of nanofluids. However, it has been shown that viscosity as an important flow characteristic needs the same attention due to its vital impact on heat transfer. Therefore, viscosity of nanofluids should be thoroughly investigated and well understood before being used in practical heat transfer applications. Unfortunately, the experimental data published so far does not yield a consistent overall picture and there is no consensus about a unified correlation approach yet.

Viscosity is an important fluid property when analyzing the fluidic behavior. When a fluid is disturbed from an equilibrium state by a velocity $u$, the dynamic viscosity $\eta$ describes the fluids tendency of energy dissipation [5]. In simple words, the dynamic viscosity is connected to the tangential force per area required to slide one layer A against another layer B with the fluid of interest in between.

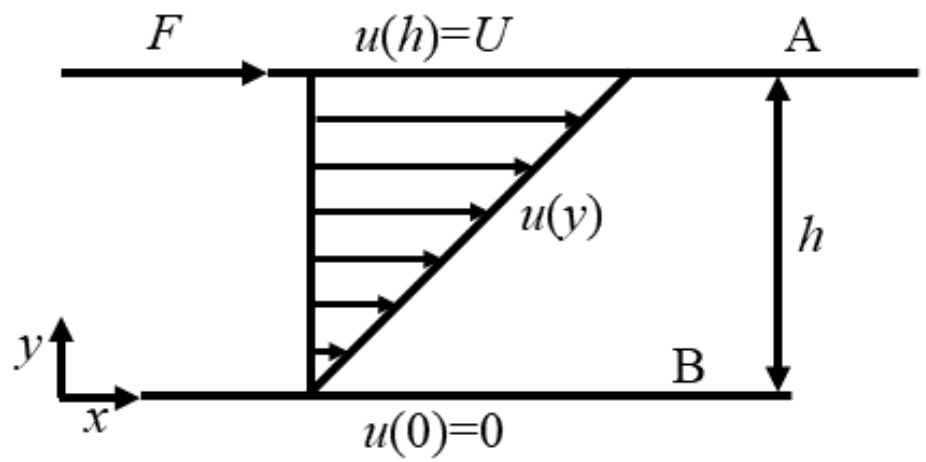

Figure 1 Simple shear of a liquid film between two plates 
In Figure 1, the force $F$ causing plate A moving with the velocity $U$ in $x$ 50 direction, creating a velocity profile in the liquid depending on $y$, is schematically 51 shown.

52 So the viscosity of a fluid can be seen as the measure of how resistive the fluid is 53 to flow, it can be defined by the mathematical expression

$$
\eta=\frac{\tau}{\dot{\gamma}}
$$

54 with the dynamic viscosity $\eta$ in $\mathrm{Pa} \cdot \mathrm{s}$, the shear stress $\tau$ in $\mathrm{N} / \mathrm{m}$ and the shear rate $55 \dot{\gamma}$ in $\mathrm{s}^{-1}$.

56 In one direction flow, the shear rate is generally expressed as:

$$
\dot{\gamma}=\frac{\mathrm{d} u}{\mathrm{~d} y}
$$

57 where $y$ is the height, $t$ is the time, and $\mathrm{d} x / \mathrm{d} t$ is the velocity $u$. The flow

58 characteristics of liquids are strongly dependent on the viscosity and are usually

59 classified as follows:

60 a) Newtonian

61

b) Time independent Non-Newtonian

62

c) Time dependent Non-Newtonian.

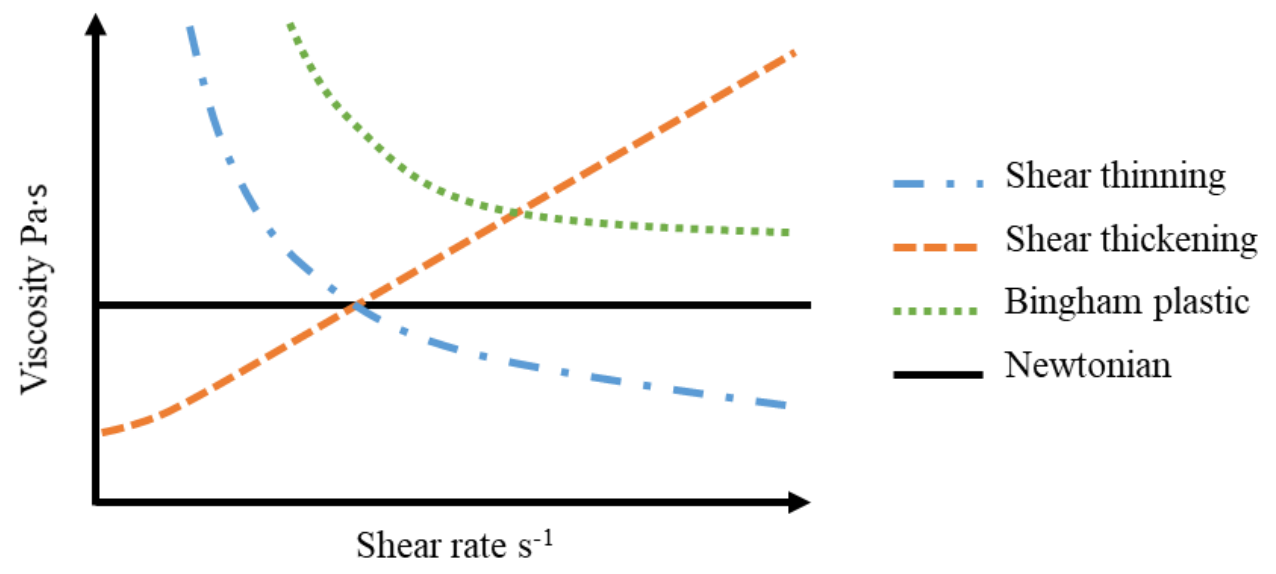

Figure 2 Different models for the change of viscosity with shear rate 
65 According to Figure 2, when the viscosity of a liquid versus shear rate remains constant, the liquid is classified as Newtonian liquid. For non-Newtonian liquids, viscosity depends on the applied shear force and time. The most common types of time independent non-Newtonian liquids include: shear thinning fluids which display a decreasing viscosity with an increasing shear rate, shear thickening fluids in which viscosity increases with an increase in shear rate and Bingham plastic fluids where the fluid must be exposed to a certain amount of force to start to behave as a fluid. In time dependent non-Newtonian fluids viscosity changes with time as the fluid continues to undergo constant shear rate [6].

The Herschel-Bulkley model takes into account changes in the effective viscosity with the shear rate by assuming the power-law expressions [7]:

$$
\eta=K \dot{\gamma}^{n-1}
$$

where $n$ is the power-law index and $K$ is a consistency index. Depending on the value of the power-law index, the material flows as a shear-thinning fluid $(n<1)$ or as a shear-thickening fluid $(n>1)$. For $n=1$, the Herschel-Bulkley model reduces to a Newtonian behavior.

Unfortunately, theories of liquid viscosity are not well established so far, as a liquid is an intermediate state of matter between gas and solid, in which particles are attracted towards each other like solid particles but with less intermolecular forces of attraction. Due to the complex nature of this intermediate state of interaction on a molecular level, it is not easy to express the thermo-physical properties of liquids by physical sound theories. Theoretical methods of calculating liquid in line with the structure of a gas introduce a short-range pair distribution function in a disordered state of the fluid, as proposed by Kirkwood et al. [8,9] and Born and Green [10]. Moreover, Quiñones-Cisneros et al. [11,12] presented a new theory called "friction theory" by introducing the total viscosity as a combination of a dilute gas term as well as a friction term to calculate the fluid viscosity. 
On the other hand, theories of liquid viscosity with solid-like structure supposed that each molecule is confined to small volumes as it interacts with a few neighbors only. So far, various researchers tried to explain fluids viscosity from this point of lattice- type of view like Brush [13], Eyrings et al. [14,15] and Collins [16]. Most of the pure theoretical models can hardly provide accurate results in ab initio approaches for viscosity of liquids. In contrast, semi-empirical and empirical methods present satisfactory results, but they lack a generality of approach. Semi-theoretical methods combine theoretical principles with experimental parameters and generally involve coupling of a viscosity model to other liquid characteristics. Most of these methods utilize corresponding state approach and/or the models are based on simplified statistical mechanics. Empirical equations involve variables like temperature, pressure, molecular mass and further properties like surface tension, vapor pressure and heat of vaporization [6]. In this regard, Guzman [17] proposed a very simple form for calculating the liquid viscosity as a function of temperature:

$$
\eta=A e^{(B / T)} .
$$

Qun-Fang et al. [18] also suggested a two-parameters model to correlate the viscosity of pure saturated liquids over a wide temperature:

$$
\ln \left(\frac{\eta V}{R T}\right)-\left(\frac{p V}{R T}\right)=\ln \left(\frac{1}{f}\right)+\left(\frac{\Delta U_{v a p}}{R T}\right)
$$

where $V$ is the volume $\left(\mathrm{m}^{3}\right), R$ is the universal gas constant $(\mathrm{J} / \mathrm{mol} \cdot \mathrm{K}), p$ is the pressure $(\mathrm{Pa}), f$ is the frequency $(\mathrm{Hz})$ and $\Delta U_{\text {vap }}$ is internal energy of the liquid upon isothermal vaporization $(\mathrm{J} / \mathrm{mol})$.

Besides pure liquids, theories and correlations have been also suggested for the viscosity of suspensions, mixtures and solutions, which are often needed to design the different unit operations and processes involved [19-21]. The first 
115 description of the effective viscosity $\eta_{n f}$ of a fluid suspension with dispersed 116 spheres dates back to Einstein [22, 23]:

$$
\frac{\eta_{n f}}{\eta_{b f}}=1+2.5 \phi
$$

117 in which $\eta_{b f}$ is the base fluid viscosity and $\phi$ is the volumetric particle fraction. 118 This approach is limited to non-interacting, spherical particles. The Einstein 119 equation predicts viscosity with an uncertainty of less than $\sim 6 \%$ for dilute 120 solutions at volume particle fractions below 1 vol. \%, in which no agglomeration 121 occur [22,24]. In 1977 the equation was extended by Batchelor et al. to account for simple particle interactions (i.e. interactions between pairs of particles) in the fluid [25]. The extended equation is valid up to a volume fraction of $10 \mathrm{vol} . \%$ of 124 particles [26]:

$$
\frac{\eta_{n f}}{\eta_{b f}}=1+2.5 \phi+6.2 \phi^{2}
$$

125 The limited applicability of Eqs. (6) and (7) inspired many authors to develop enhanced formulations of the Einstein equation or develop completely new approaches, while all of the equations contain parameters which have to be fitted to experimental data. Reviews about these approaches are given by Khanafer et al. [27], Mahbubul et al. [28], Sundar et al. [29] and Mishra et al. [30]. Many of the given formulae are series expansions that simplify to Eq. 7 when higher order terms are neglected. However, these review articles conclude, that at present no theoretical model can predict the nanofluids viscosity sufficiently in a broad range of parameters.

According to the correlations and review papers mentioned above, some authors observed Newtonian viscosity behavior, whereas others noted shear thinning viscosity behavior, only a few of them measured shear thickening behavior in nanofluids. Prasher et al. [31] found, that $\mathrm{Al}_{2} \mathrm{O}_{3}$-propylene glycol nanofluids with up to 2 vol. \% particle fraction show Newtonian behavior. This is in agreement with findings of Chandrasekar et al. [32] for $\mathrm{Al}_{2} \mathrm{O}_{3}$-water 
nanofluids with up to 5 vol. \%. Similar results are also shown by Anoop et al. [33] for $\mathrm{Al}_{2} \mathrm{O}_{3}$-water nanofluids with various particle fractions up to 6 vol. \%. In contrast, Yang et al. [34] measured shear thinning behavior of $\mathrm{Al}_{2} \mathrm{O}_{3}$-water nanofluids with $1.28 \mathrm{vol}$. \% at lower shear rates, but Newtonian behavior at higher shear rates. This viscosity behavior seems to be similar to that of Binghamplastics, but it does not seem to be adequate to classify fluids of this type here, since the reproducibility of the effect is unknown yet. However, when Yang et al. reduced the effective particle size by adding stabilizer and thus limited agglomeration, the nanofluid showed Newtonian behavior over the complete range of shear rates between 10 and $1000 \mathrm{~s}^{-1}$. Buschmann et al. [35] measured the viscosity of different nanofluid samples. Among them were higher concentrated samples (12.7 - 13.0 vol. \%) of $\mathrm{TiO}_{2}$ - and $\mathrm{Al}_{2} \mathrm{O}_{3}$-nanofluids. They report that non-Newtonian behavior could be seen only at very low shear rates. In a benchmark test from 2009 several laboratories investigated $\mathrm{SiO}_{2}$ nanoparticles in $\mathrm{H}_{2} \mathrm{O}$ and $\mathrm{Al}_{2} \mathrm{O}_{3}$ nanoparticles in oil [36]. In the test, the $\mathrm{SiO}_{2}-\mathrm{H}_{2} \mathrm{O}$ nanofluid showed shear thinning behavior up to shear rate of about $10 \mathrm{~s}^{-1}$ and Newtonian behavior for higher shear rates whereas the $\mathrm{Al}_{2} \mathrm{O}_{3}$-oil nanofluid did not show significant deviation from Newtonian behavior in the range of between 0.1 to $1000 \mathrm{~s}^{-1}$.

In contrast to the shear thinning and the Newtonian behavior of nanofluids, which were widely observed, shear thickening effects with increasing shear rates are not often mentioned in the literature. It was observed only by few researchers, for instance, it was described by Tseng et al. $[37,38]$ who reported a critical shear rate, at which viscosity begins to increase with shear rate. They found for $\mathrm{Al}_{2} \mathrm{O}_{3}$ water nanofluids, that the onset shear rate increases with the particle volume fraction. For volume fraction of 0.05 and a temperature of $T=25^{\circ} \mathrm{C}$ they found the critical shear rate of about $\dot{\gamma}_{m} \approx 90 \mathrm{~s}^{-1}$ at which shear thickening behavior begins. In another experiment, Tseng et al. [39] examined the viscosity of a dispersion of indium tin oxide (ITO) nanoparticles in water with $0.5-2$ wt. \% in 
the presence of ammonium polyacrylate $\left(\mathrm{NH}_{4} \mathrm{PA}\right)$ as a surfactant. From the result

170 they concluded that critical shear-rate for the onset of dilatancy appears to reduce

171 linearly with an increase of $\phi$. A similar trend was presented for aqueous alumina

172 and barium titanate suspensions with $\mathrm{NH}_{4} \mathrm{PA}$ as surfactant [40]. In addition to

173 Tseng et al. [41-43], who observed shear thickening behavior in nanofluids for

174 the first time, some other researchers also reported shear thickening behavior of

175 nanofluids [44-46] afterwards. Further findings from literature are summarized in

176 Table 1.

177 Table 1 Reported behavior of $\mathrm{CuO}$ and $\mathrm{Al}_{2} \mathrm{O}_{3}$ nanofluid viscosity with the shear rate from literature.

\begin{tabular}{|c|c|c|c|c|c|}
\hline Authors & $\begin{array}{l}\text { Nanoparticle/ } \\
\text { base fluid }\end{array}$ & $\begin{array}{c}\phi \\
(\text { vol. \%) }\end{array}$ & $\begin{array}{l}\text { Shear rate } \\
\text { range }(1 / S)\end{array}$ & Findings & surfactant \\
\hline $\begin{array}{l}\text { Garg et al. } \\
{[47]}\end{array}$ & $\mathrm{CuO} / \mathrm{EG}$ & $0.6,1.5$ & $3-3000$ & $\begin{array}{l}\text { Nanofluid demonstrated a } \\
\text { clear Newtonian behavior }\end{array}$ & No \\
\hline $\begin{array}{l}\text { Hojjat et al. } \\
\text { [48] }\end{array}$ & $\begin{array}{l}\mathrm{Al}_{2} \mathrm{O}_{3} / \mathrm{H}_{2} \mathrm{O} \\
\mathrm{CuO} / \mathrm{H}_{2} \mathrm{O}\end{array}$ & $0.1,0.5$ & $350-950$ & $\begin{array}{l}\text { An apparent shear } \\
\text { thinning behavior was } \\
\text { observed }\end{array}$ & No \\
\hline $\begin{array}{l}\text { Anoop et al. } \\
{[33]}\end{array}$ & $\begin{array}{l}\mathrm{Al}_{2} \mathrm{O}_{3} / \mathrm{H}_{2} \mathrm{O} \\
\mathrm{Al}_{2} \mathrm{O}_{3} / \mathrm{EG}\end{array}$ & $1,4,6$ & $10-1000$ & $\begin{array}{l}\text { Nanofluids showed an } \\
\text { approximate Newtonian } \\
\text { behavior }\end{array}$ & $\begin{array}{l}\text { Not } \\
\text { mentioned }\end{array}$ \\
\hline $\begin{array}{l}\text { Aladag et al. } \\
\text { [44] }\end{array}$ & $\begin{array}{l}\mathrm{CuO} / \mathrm{EG} \\
\mathrm{Al}_{2} \mathrm{O}_{3} / \mathrm{H}_{2} \mathrm{O}\end{array}$ & $1 \mathrm{wt} \%$ & $0-4000$ & $\begin{array}{l}\text { Nanofluid showed a } \\
\text { strong shear thickening } \\
\text { behavior over entire } \\
\text { range }\end{array}$ & Yes \\
\hline $\begin{array}{l}\text { Namburu et } \\
\text { al. [49] }\end{array}$ & $\begin{array}{l}\mathrm{Al}_{2} \mathrm{O}_{3} /\left(\mathrm{H}_{2} \mathrm{O}+\right. \\
\mathrm{EG})\end{array}$ & $\begin{array}{l}1,2,3,4 \\
5,6.12\end{array}$ & $0-8$ & $\begin{array}{l}\text { Nanofluid indicated } \\
\text { Newtonian behavior }\end{array}$ & No \\
\hline $\begin{array}{l}\text { Tseng and } \\
\text { Wu. [38] }\end{array}$ & $\mathrm{Al}_{2} \mathrm{O}_{3} / \mathrm{H}_{2} \mathrm{O}$ & $\begin{array}{l}3,6,11 \\
16\end{array}$ & $1-1000$ & $\begin{array}{l}\text { Nanofluids showed shear } \\
\text { thinning behavior in lower } \\
\text { shear rate followed by } \\
\text { shear thickening behavior } \\
\text { in higher shear rates }\end{array}$ & No \\
\hline
\end{tabular}


$\begin{array}{llll}\text { Kole and } & \mathrm{Al}_{2} \mathrm{O}_{3} / \text { engine } & 0.1,0.4, & 0-90 \\ \text { Dey [50] } & \text { oil } & 0.7,1,1.5 & \end{array}$

Tseng and $\quad \mathrm{Al}_{2} \mathrm{O}_{3} / \mathrm{H}_{2} \mathrm{O}$

$\mathrm{Wu}$ [37]

Chandrasek

ar et al.[32]
$\mathrm{Al}_{2} \mathrm{O}_{3} / \mathrm{H}_{2} \mathrm{O}$

$1,2,3,4$

5
$1,3,5,10, \quad 1-1000$

15
For low $\mathrm{Al}_{2} \mathrm{O}_{3}$ loading, the nanofluid exhibited

Newtonian behavior,

Yes

while for higher loading

(>0.004) shear thinning

behavior was observed

Nanofluids exhibited a

transition from shear

thinning behavior to shear

No

thickening behavior

The nanofluid showed

Newtonian behavior up to

$2 \%$ volume fraction and

No

for higher volume fraction

a slight shear thickening

was observed

179 To underline the problem of the proper interpretation of all data published, the

180 viscosity of $\mathrm{Al}_{2} \mathrm{O}_{3} / \mathrm{H}_{2} \mathrm{O}$ nanofluid as measured by Tseng and $\mathrm{Wu}$ [37] was compared with measurements by Hojjat et al. [48] in the range of 300 to $1000 \mathrm{~s}^{-1}$

182 in Figure 3 because of a comparable nanofluid and shear rate range. Despite these

183 comparable boundary conditions, a contrasting behavior of the viscosity as a

184 function of shear rate is observed. This might be due to different approaches of

185 nanofluids preparation, e.g. stabilizers, nanoparticles properties or different

186 methods of measurement.

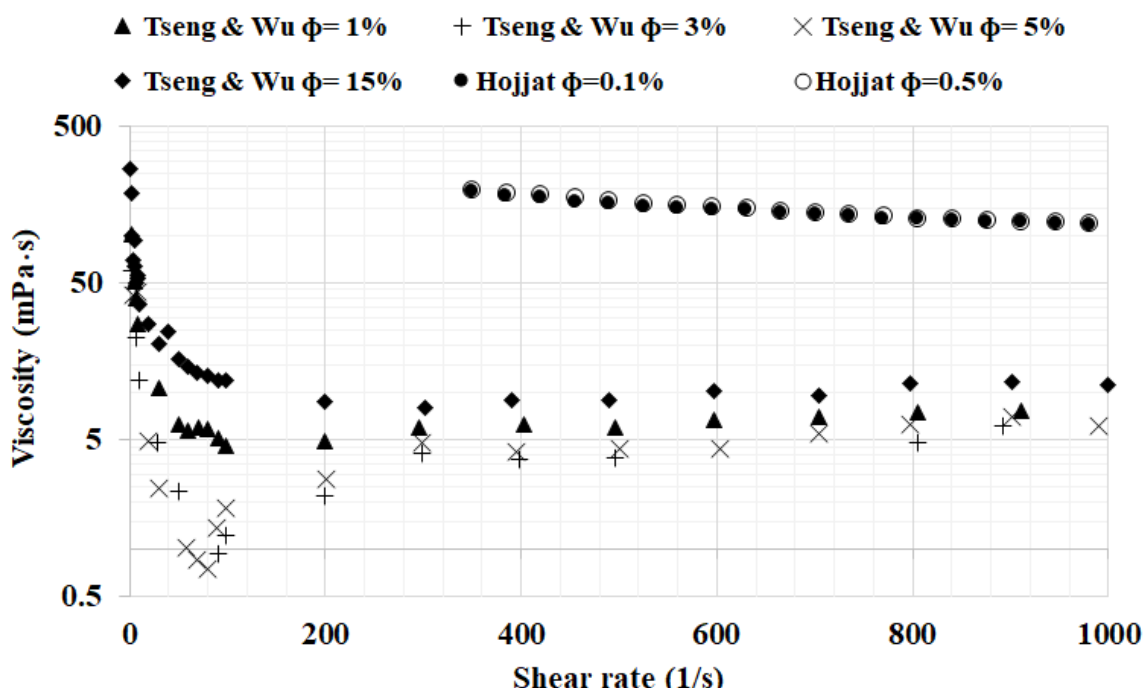

Figure 3 Comparison of Tseng and $\mathrm{Wu}$ [37] with Hojjat et al. [48] results 
To investigate the rheological behavior, the viscosity of different types of nanofluids was measured in a wide range of volume fraction, temperature and shear rate. The results are then compared with literature data, followed by a discussion.

\section{Experimental Procedure}

194 The experimental results shown in this contribution have been gained with two different measurement procedures. Both sets of data were used later to give the heat transfer performance of these nanofluids. As the results were not satisfying regarding the heat transfer, the data on viscosity has never been published. However, more and more reports about Newtonian, shear thinning or shear thickening behavior emerged in the literature, so we now decided to re-analyze the existing data to shed some light on the matter of nanofluid viscosity.

The first set of data was recorded in the year 2002 at the Helmut-Schmidt University (HSU), the university of the Federal Armed Forces in Hamburg, Germany. Two different particle types were investigated. The first particle type were AEROSIL $200 \mathrm{SiO}_{2}$ nanoparticles and the second one were DEGUSSA c-type $\mathrm{Al}_{2} \mathrm{O}_{3}$ nanoparticles. Both particle types were dispersed in DI water as well as ethylene glycol. The Nanofluids were prepared by dispersing nanoparticles in proper concentrations in base fluids. After mixing them the suspension was homogenized by using a high performance mixer (model T25 digital ULTRATURRAX) for about 30 min to thoroughly mix the nanofluid. Then, nanofluids were stabilized by ultrasonic treatment and were kept in ultrasonic bath for about

$2112 \mathrm{~h}$. Following this, a high power ultrasonication using an ultrasonic disruptor of 212 KLN Sys 587 model was employed and inserted into the nanofluid solution for 213 about $1 \mathrm{~h}$. Further deagglomeration was carried out by passing the suspension 214 through a high pressure shearing process in order to achieve a very homogeneous 
nanofluid. Unfortunately, no measurement of the particles size distribution has 216 been conducted at that time, the primary particle size is in both cases $20 \mathrm{~nm}$.

217 The viscosity was measured using a USD200 (Physica) rheometer with the 218 cone and plate geometry according to the standard of DIN 53019, where the cone 219 diameter was $75 \mathrm{~mm}$, the cone angle was $1^{\circ}$ and the gap between cone and plate 220 was $0.05 \mathrm{~mm}$, as can be seen in Figure 4a. Measurements were conducted at 221 different temperatures $\left(20^{\circ} \mathrm{C}-60^{\circ} \mathrm{C}\right)$, different shear rates $\left(10 \mathrm{~s}^{-1}-500 \mathrm{~s}^{-1}\right)$ and volume fractions of $(0.5 \%, 1 \%$ and $2 \%)$. Every experiment was conducted twice to obtain more accurate results.

The second set of data is a measurement series conducted by the BASF Chemical Company in Ludwigshafen, Germany, in the year 2005. The nanofluids analyzed are an ethylene-glycol based $\mathrm{CuO}$ and a water based $\mathrm{Al}_{2} \mathrm{O}_{3}$ nanofluid which both were purchased from the U.S. company Nanophase Technologies Corporation. The $\mathrm{CuO}$ nanofluids were tested in volume fractions of $2.5 \%, 5 \%$ and $15 \%$, the $\mathrm{Al}_{2} \mathrm{O}_{3}$ nanofluids were examined in volume fractions of $2.5 \%, 5 \%$, $15.8 \%, 18.7 \%$ and $22 \%$. The rheological analysis was performed over a temperature range of $25{ }^{\circ} \mathrm{C}-80{ }^{\circ} \mathrm{C}$ using a Physica $\mathrm{MC} 1$ rheometer. The analyzed shear rates ranged from 0 to $1200 \mathrm{~s}^{-1}$. Moreover, in order to observe possible hysteresis effects in the viscosity behavior, measurements with increasing and decreasing values of shear rates were performed.

The Physica MC1 double gap rheometer works according to DIN54433 and 236 consists of concentric cylinders, it represents an accurate method of measuring the viscosity of nanofluids over a wide range of shear rates. According to the DIN standard, an inner cylinder is mounted in the center of a cup, thus, the cross section of the cup is showing an annular gap as it can be seen in Figure $4 \mathrm{~b}$. The rotating bob is like a hollow cylinder, therefore wetting both inner and outer surfaces which leads to an increase in shear area. 


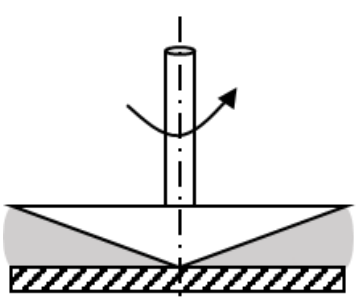

(a)

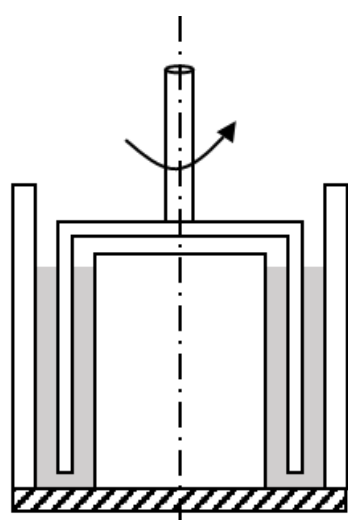

(b)

Figure 4 Schematic setup of measurement principle (a) according to DIN 53019 on the left side (b) according to DIN 54453 on the right side

245 The particle size distribution of the second set of nanofluids was measured using 246 analytical ultracentrifugation. The results of these measurements are summarized 247 in Table 2 . The value $D_{50}$ denotes the mean particle size, whereas the $D_{10}$ and $D_{90}$ 248 provide information about the width of the size distribution.

Table 2 Particle size distribution from analytical ultracentrifugation

\begin{tabular}{llcc}
\hline & & Mass distribution & Quantity distribution \\
\hline \multirow{4}{*}{$\mathrm{CuO}$ in EG } & $D_{10}$ in $\mathrm{nm}$ & 78 & 66 \\
& $D_{50}$ in $\mathrm{nm}$ & 119 & 90 \\
& $D_{90}$ in $\mathrm{nm}$ & 187 & 132 \\
& $D_{10}$ in $\mathrm{nm}$ & 55 & 49 \\
& $D_{50}$ in nm & 91 & 61 \\
$\mathrm{Al}_{2} \mathrm{O}_{3}$ in $\mathrm{H}_{2} \mathrm{O}$ & $D_{90}$ in $\mathrm{nm}$ & 170 & 96 \\
& & & \\
\hline
\end{tabular}

\section{Results and Discussion}

251 In this part the results of the viscosity measurement are shown for both sets. 252 Firstly, the viscosity results of $\mathrm{SiO}_{2}$ in ethylene glycol, $\mathrm{SiO}_{2}$ in water as well as $253 \mathrm{Al}_{2} \mathrm{O}_{3}$ in ethylene glycol and $\mathrm{Al}_{2} \mathrm{O}_{3}$ in water from Hamburg University of the 254 Federal Armed Forces Germany are presented. Then, results of nanofluids 
consisting of $\mathrm{Al}_{2} \mathrm{O}_{3}$ in water, $\mathrm{CuO}$ in ethylene glycol, from BASF company 256 measurements are shown.

257

258

259

260

261

262

263

264

265 266

267

268 269

\subsection{Viscosity measurement of the Hamburg University of the Federal Armed Forces Germany}

The viscosity of $\mathrm{SiO}_{2}$ and $\mathrm{Al}_{2} \mathrm{O}_{3}$ nanofluids with different particle volume fractions at temperatures between $20{ }^{\circ} \mathrm{C}$ to $60{ }^{\circ} \mathrm{C}$ were measured two times by employing the rotational viscometer for shear rates from 10 to $500 \mathrm{~s}^{-1}$. Figures 5 and 6 show the results of the measurements for $\mathrm{SiO}_{2}$ particles dispersed in ethylene glycol and water at the volume fraction of $\phi=0.5 \%$, respectively. As it can be seen, the viscosity of $\mathrm{SiO}_{2}$-ethylene glycol shows only a minimal influence of shear thinning, whereas for $\mathrm{SiO}_{2}$-water nanofluid a clear shear thinning behavior is observed.

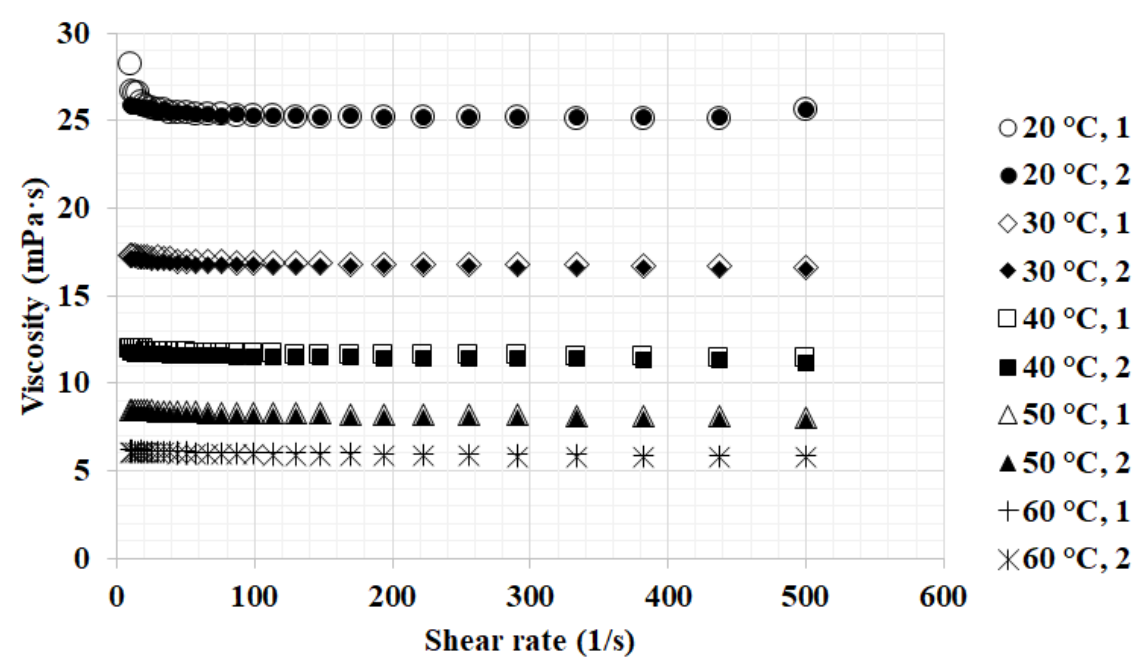

Figure 5 Measured viscosity of a $\mathrm{SiO}_{2}$ - ethylene glycol nanofluid with $\phi=0.5 \%$, all measurements were performed two times labeled with 1 and 2 


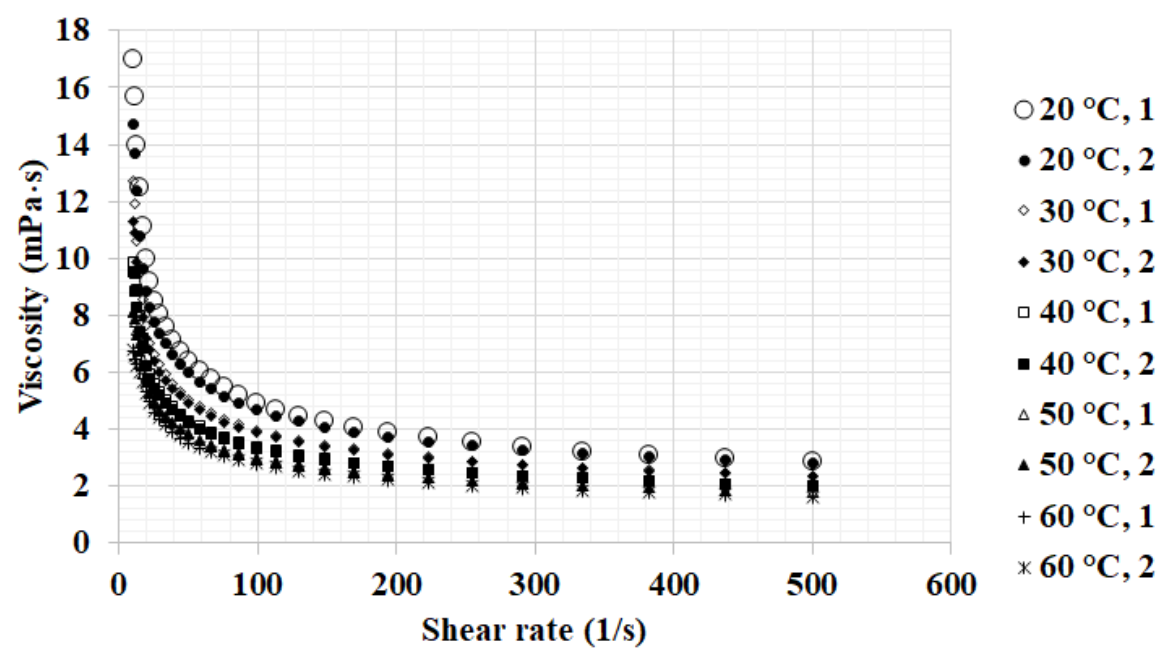

270

271

272

273 Measurement results for $\mathrm{Al}_{2} \mathrm{O}_{3}$ - water and $\mathrm{Al}_{2} \mathrm{O}_{3}$ - ethylene glycol nanofluids at 274 the volume fraction of $\phi=0.5 \%$ are shown in Figures 7 and 8. For $\mathrm{Al}_{2} \mathrm{O}_{3}-\mathrm{Water}$ 275 276 277 278 279 280 of rheological behavior are observed to a minor extend (Figure 8).

Figure 6 Measured viscosity of a $\mathrm{SiO}_{2}$ - water nanofluid with $\phi=0.5 \%$, all measurements were performed two times labeled with 1 and 2 nanofluid in Figure 7, shear thinning behavior is observed at low shear rates, changing to Newtonian behavior at moderate shear rates and to obvious shear thickening behavior at higher shear rates. Whereas, for $\mathrm{Al}_{2} \mathrm{O}_{3}$ - ethylene glycol nanofluid shear thinning behavior followed by Newtonian behavior can be seen 279 for temperatures of $30^{\circ} \mathrm{C}$ to $60^{\circ} \mathrm{C}$. Only for a temperature of $20^{\circ} \mathrm{C}$ all three types

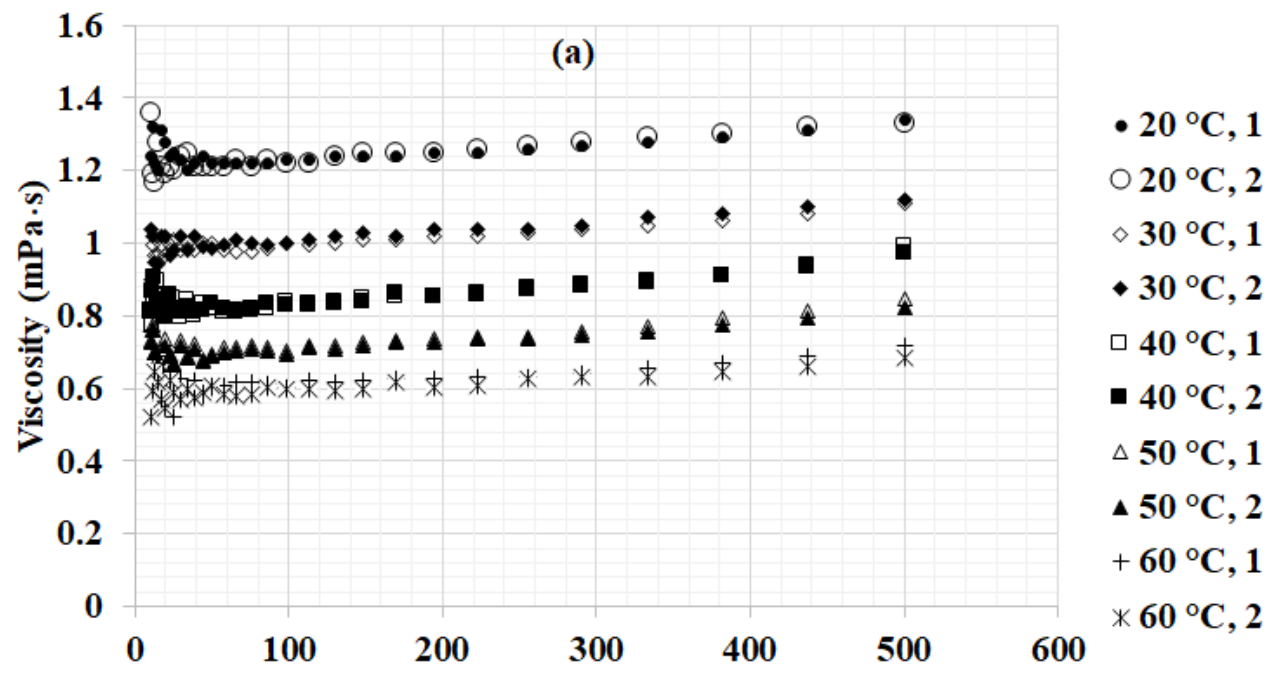

Shear rate $(1 / s)$ 


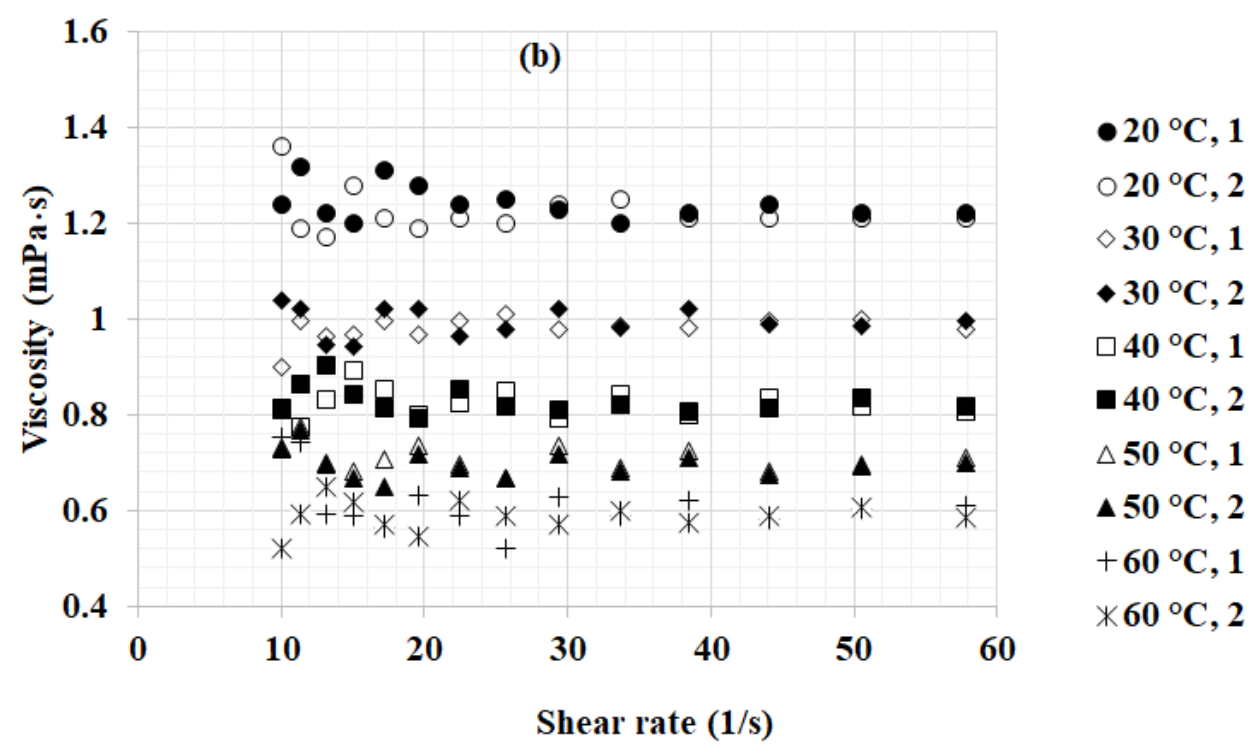

Figure 7 Measured viscosity of a $\mathrm{Al}_{2} \mathrm{O}_{3}$ - water nanofluid with $\phi=0.5 \%$, all measurements were performed two times labeled with 1 and 2. (a) in a shear rate range from $5 \mathrm{~s}^{-1}$ to $500 \mathrm{~s}^{-1}$

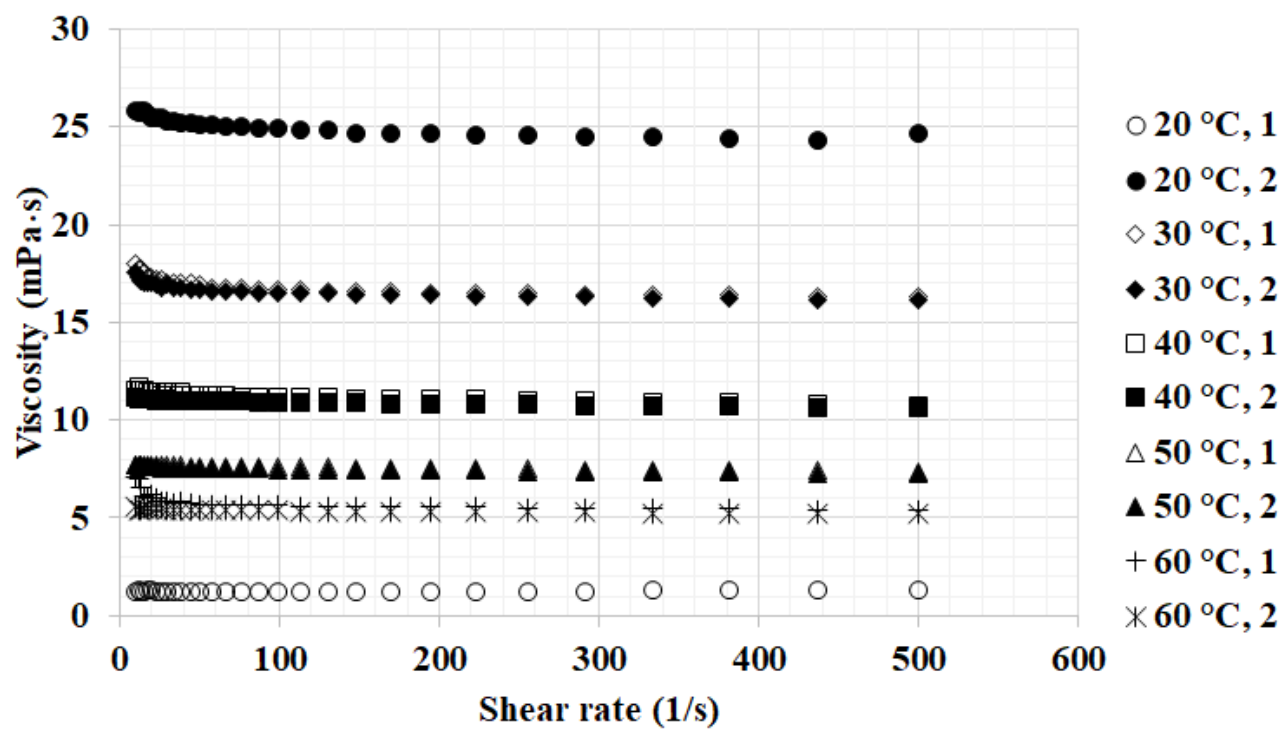

Figure 8 Measured viscosity of a $\mathrm{Al}_{2} \mathrm{O}_{3}$ - ethylene glycol nanofluid with $\phi=0.5 \%$, all measurements were performed two times labeled with 1 and 2

290 Moreover, experimental results for $\mathrm{Al}_{2} \mathrm{O}_{3}$ - ethylene glycol at a volume fraction 291 of $\phi=1 \%$ and $\mathrm{Al}_{2} \mathrm{O}_{3}$ - water at the volume fraction of $\phi=2 \%$ are shown in 292 Figures 9 and 10, respectively. In both nanofluids shear thinning behavior is 293 observed, however it is more obvious in the $\mathrm{Al}_{2} \mathrm{O}_{3}$ - water nanofluid. 


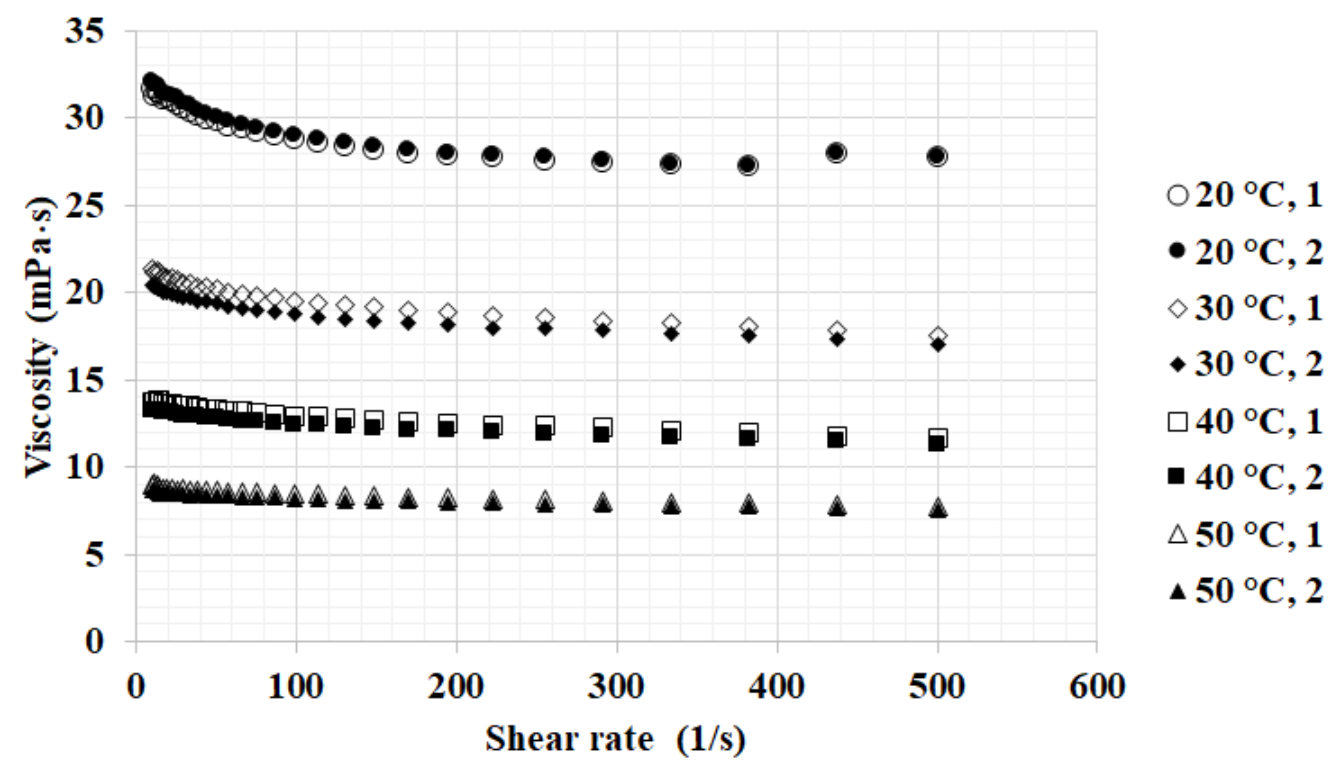

294

Figure 9 Measured viscosity of a $\mathrm{Al}_{2} \mathrm{O}_{3}$ - ethylene glycol nanofluid with $\phi=1 \%$, all 296 measurements were performed two times labeled with 1 and 2

297

298

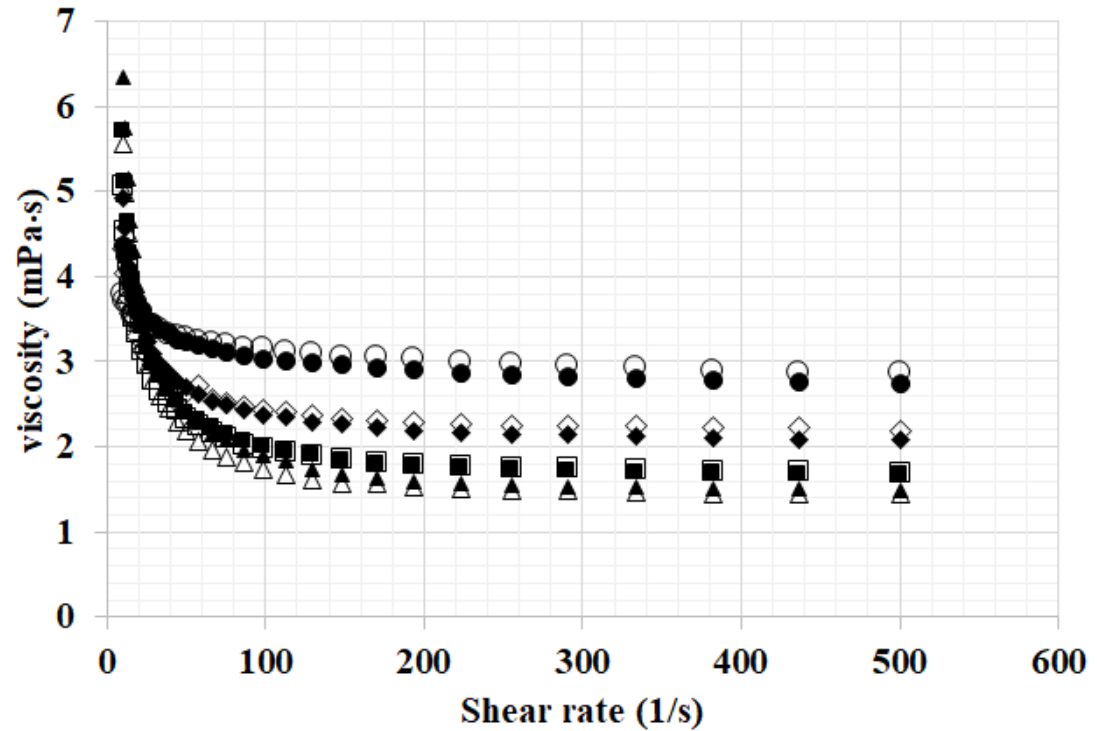

$\bigcirc 20^{\circ} \mathrm{C}, 1$

$\bullet 20^{\circ} \mathrm{C}, 2$

$\diamond 30^{\circ} \mathrm{C}, 1$

$\rightarrow 30^{\circ} \mathrm{C}, 2$

$\square 40^{\circ} \mathrm{C}, 1$

- $40^{\circ} \mathrm{C}, 2$

$\triangle 50^{\circ} \mathrm{C}, \mathbf{1}$

$\triangle 50{ }^{\circ} \mathrm{C}, 2$

299

Figure 10 Measured viscosity of a $\mathrm{Al}_{2} \mathrm{O}_{3}$ - water nanofluid with $\phi=2 \%$, all measurements 300 were performed two times labeled with 1 and 2

301 
In this section the results of the viscosity measurements at the BASF Company are shown. The results of BASF are split into two sections, beginning with lower volume fractions $\phi<10 \%$, followed by higher volume fractions $\phi>10 \%$.

\subsubsection{Viscosity measurement for volume fractions $<10 \%$}

Using a double gap viscometer, the viscosities of $\mathrm{Al}_{2} \mathrm{O}_{3}$ and $\mathrm{CuO}$ nanofluids with different particle concentrations at temperature of $25{ }^{\circ} \mathrm{C}, 50{ }^{\circ} \mathrm{C}$ and $80{ }^{\circ} \mathrm{C}$ were measured for increasing (up) and decreasing (down) shear rates. Figure 11 shows the results of the measurements for $\mathrm{CuO}$ particles dispersed in ethylene glycol at the volume fraction of $\phi=2.5 \%$ for three different temperatures of $25{ }^{\circ} \mathrm{C}, 50{ }^{\circ} \mathrm{C}$, and $80{ }^{\circ} \mathrm{C}$. At low shear rates, shear thinning behavior can be seen, changing to Newtonian behavior at higher shear rates. Moreover, small hysteresis effects can be seen, which will be discussed later. Also, a slight increase in viscosity is observable towards higher shear rates at $T=80^{\circ} \mathrm{C}$. Recalling the model fluids shown in Figure 2, the description of a Bingham plastic would suit the shown data best. However, this expression will not be used in the following, since the effects causing the shear thinning maybe not fluid-intrinsic, but are possibly produced by complex particle interactions that are not entirely known yet.

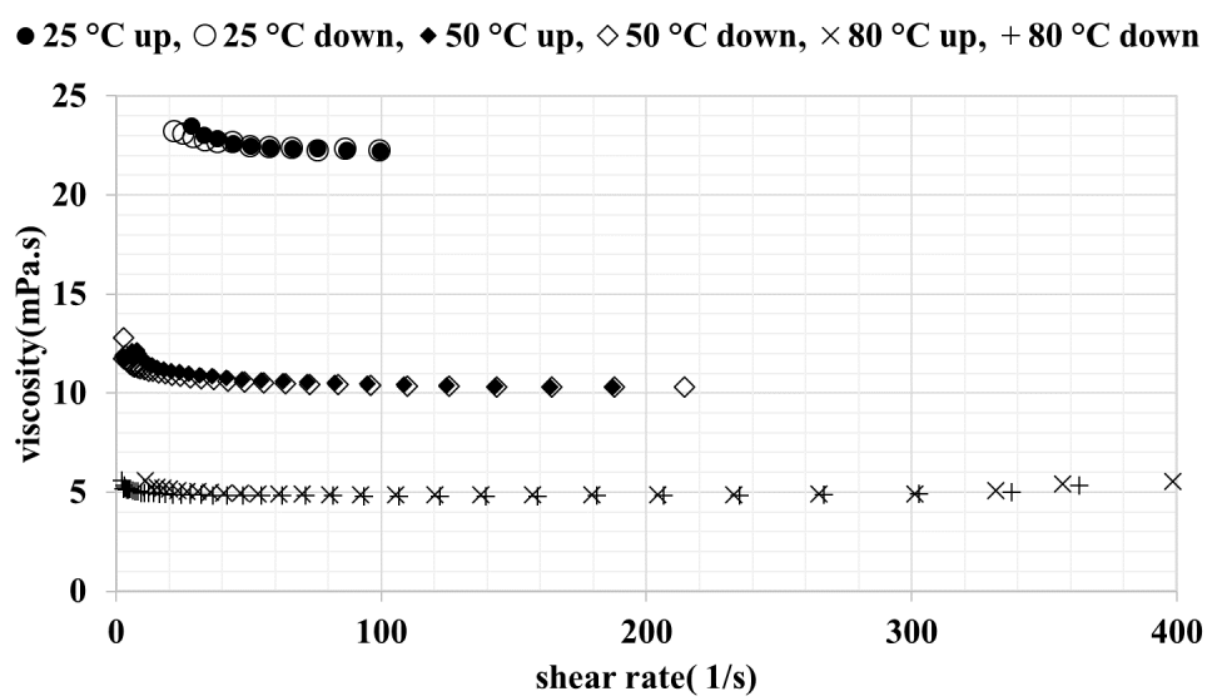


Measurements for $\mathrm{CuO}$ in ethylene glycol were repeated with a higher volume 323 fraction of $\phi=5 \%$ for a wider range of shear rates according to Figure 12 .

$\bullet 25^{\circ} \mathrm{C}$ up, $\bigcirc 25^{\circ} \mathrm{C}$ down, $\bullet 50^{\circ} \mathrm{C}$ up, $\diamond 50^{\circ} \mathrm{C}$ down, $\times 80^{\circ} \mathrm{C}$ up, $+80 \mathrm{C}$ down

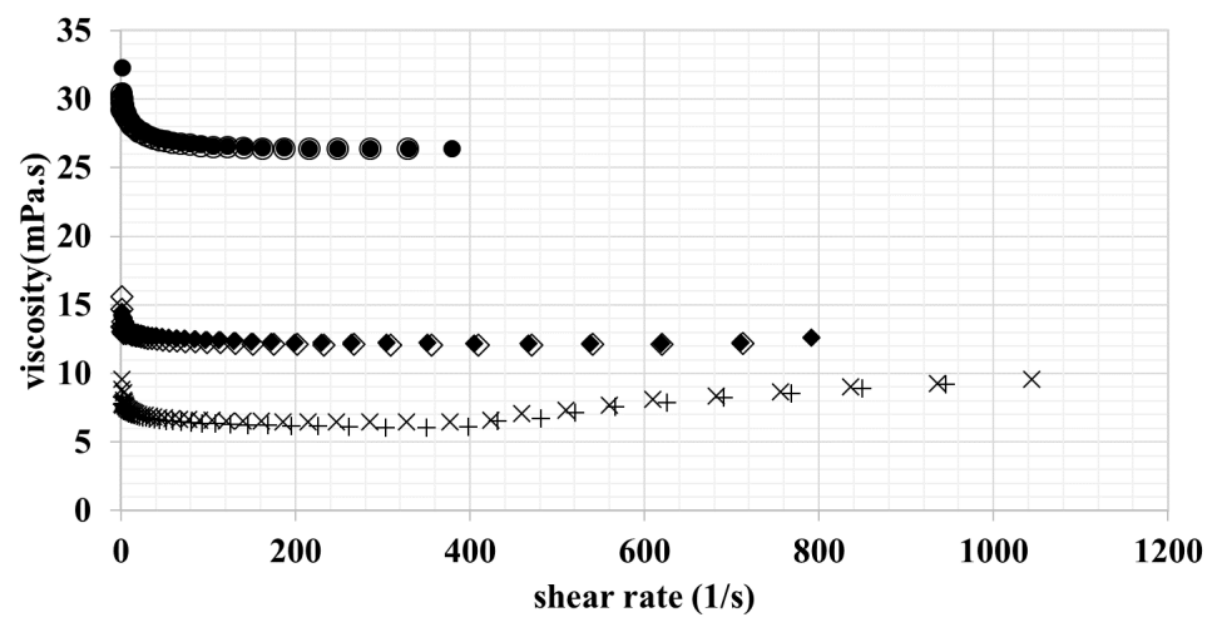

324

Figure 12 Measured viscosity of a CuO- ethylene glycol nanofluid with $\phi=5 \%$

326 Similar to the results obtained for $\phi=2.5 \%$, shear thinning behavior is observed

327 at low shear rates, followed by Newtonian behavior at moderate shear rates and 328 slight shear thickening behavior at higher shear rates. It is also worth noting that 329 an increase of temperature leads to an onset of shear thickening behavior at lower 330 shear rates. The results for a particle fraction of $\phi=5 \%$ of $\mathrm{Al}_{2} \mathrm{O}_{3}$ particles in 331 water are presented in Figure 13. The measurement results of $\mathrm{Al}_{2} \mathrm{O}_{3}$ particles in 332 water are a good example to observe three distinct rheological behaviors of 333 nanofluids clearly. Furthermore, strong hysteresis effects can also be identified 334 from these results. The discussion of these observations follows in chapter 3.3. 


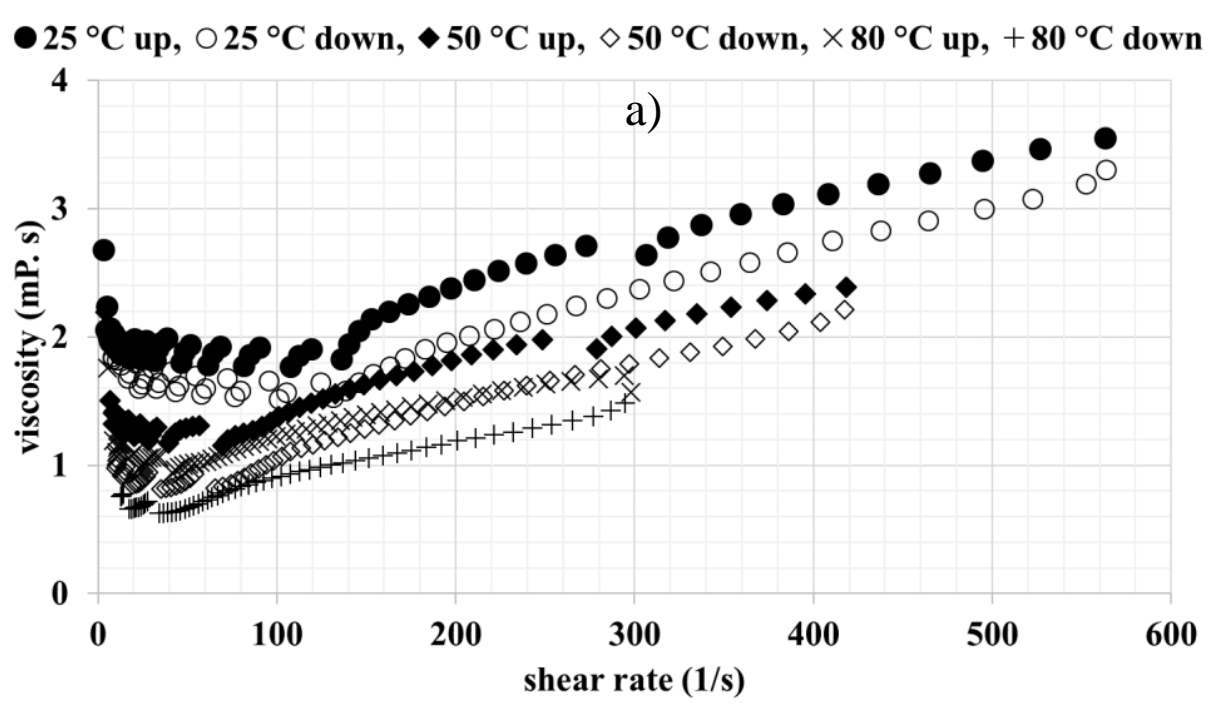

336

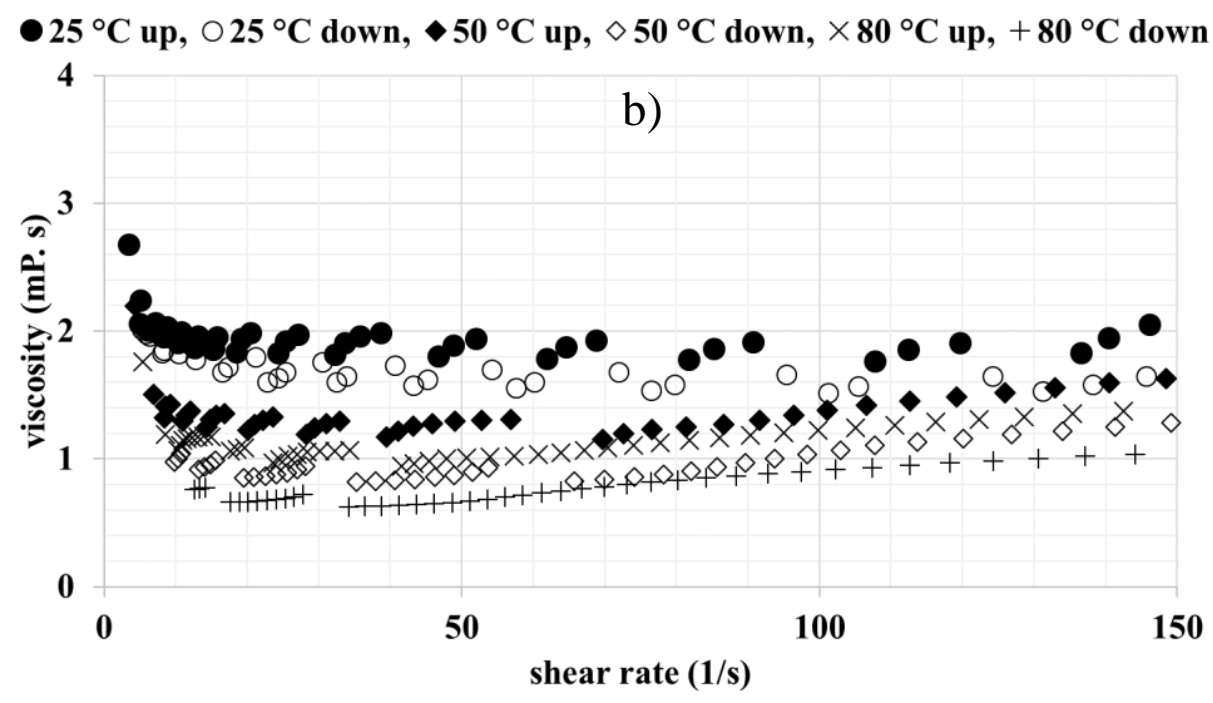

337

338 Figure 13 Measured viscosity of $\mathrm{Al}_{2} \mathrm{O}_{3}$-water nanofluid with $\phi=5 \%$ in a shear range of a) 0 to $600 \mathrm{~s}^{-1}$ and in the range of b) 0 to $150 \mathrm{~s}^{-1}$

341 In the following, measurement results for volume fractions higher than $10 \%$ are 342 shown. Measured viscosity data for $\mathrm{Al}_{2} \mathrm{O}_{3}$-water nanofluids with $\phi=15.8 \%$, $343 \phi=18.7 \%$ and $\phi=22 \%$ at $25^{\circ} \mathrm{C}$ are shown in Figure 14. 


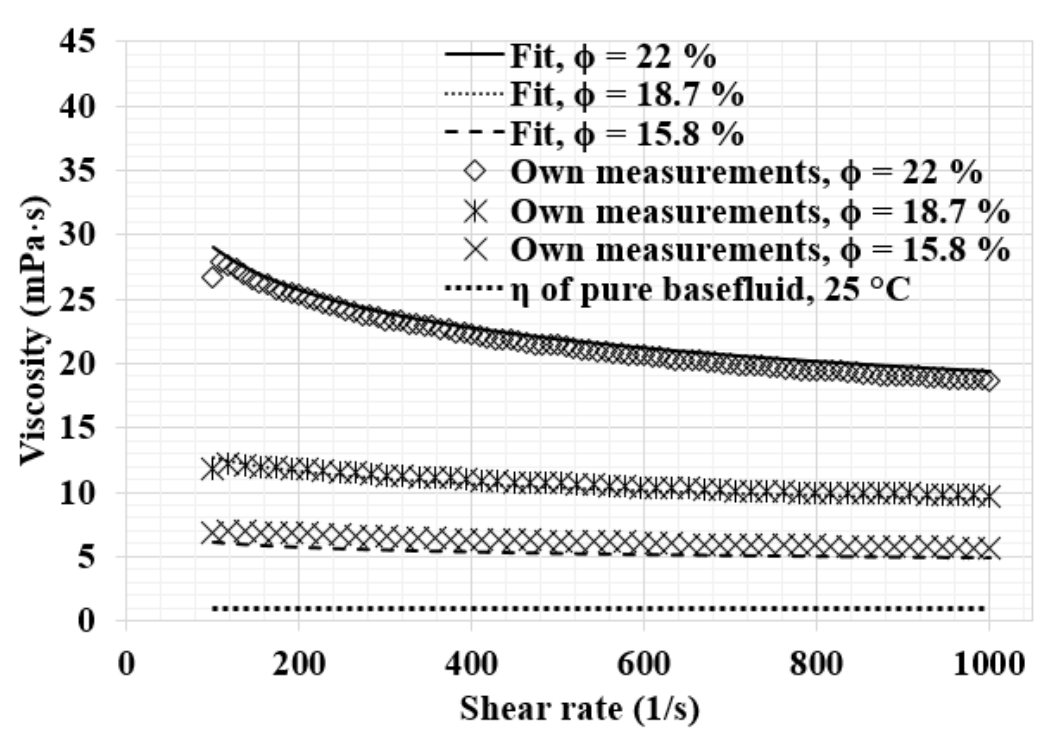

345

348 Strong shear thinning behavior is observed for $\phi=22 \%$, whereas for lower 349 particle concentrations the fluids tend to Newtonian behavior. In such cases, a 350 power law equation can be fitted to the measured data using a least square fit, in 351

$$
\begin{aligned}
& \eta=k \cdot \dot{\gamma}^{n-1} \\
& k=\eta_{\mathrm{bf}}\left(1+A_{\mathrm{k}}-A_{\mathrm{k}} \exp \left(B_{\mathrm{k}} \varphi\right)\right) \\
& n=\sqrt{1-A_{\mathrm{n}} \varphi} \\
& A_{\mathrm{k}}=-0.049002, B_{\mathrm{k}}=33.30365, A_{\mathrm{n}}=6.67627
\end{aligned}
$$

Moreover, results of viscosity measurements for $\mathrm{CuO}$ nanoparticles in 353 ethylene glycol at different shear rates are shown in Figure 15. The viscosity data 354 axes are scaled logarithmically, while shear rates are shown in logarithmic scaling in Figure 15a, and in linear scaling in Figure 15b. The particle volume fraction of 356 the nanofluid samples is $\phi=15 \%$. As for the $\mathrm{Al}_{2} \mathrm{O}_{3}$-water nanofluids, the data are correlated using a power law approach, the fitted equations for the $\mathrm{CuO}$ - ethylene 358 


$$
\begin{aligned}
& \eta=k \cdot \dot{\gamma}^{n-1} \\
& k=A_{k}-B_{k} \eta_{\mathrm{bf}}+C_{k} \eta_{b f}^{2} \\
& n=A_{n}+B_{n} \eta_{b f}+C_{n} \eta_{b f}^{2} \\
& A_{\mathrm{k}}=12.5369, B_{\mathrm{k}}=905.049, C_{\mathrm{k}}=28806 \\
& A_{n}=0.143899, B_{\mathrm{n}}=4.86454, C_{\mathrm{n}}=223.295
\end{aligned}
$$

359 In Figure 15 , values for $\mathrm{CuO}$ - ethylene glycol are shown for $25^{\circ} \mathrm{C}, 50{ }^{\circ} \mathrm{C}$ and $36080{ }^{\circ} \mathrm{C}$, respectively. The base fluid viscosity data is a function of the temperature 361 and therefore accounts for the temperature dependence of the given curve fits. 362 Similar to the values recorded for $\mathrm{Al}_{2} \mathrm{O}_{3}$, the $\mathrm{CuO}$ ethylene glycol nanofluid has 363 a shear thinning behavior with a seemingly asymptotical trend towards high shear 364 rates.

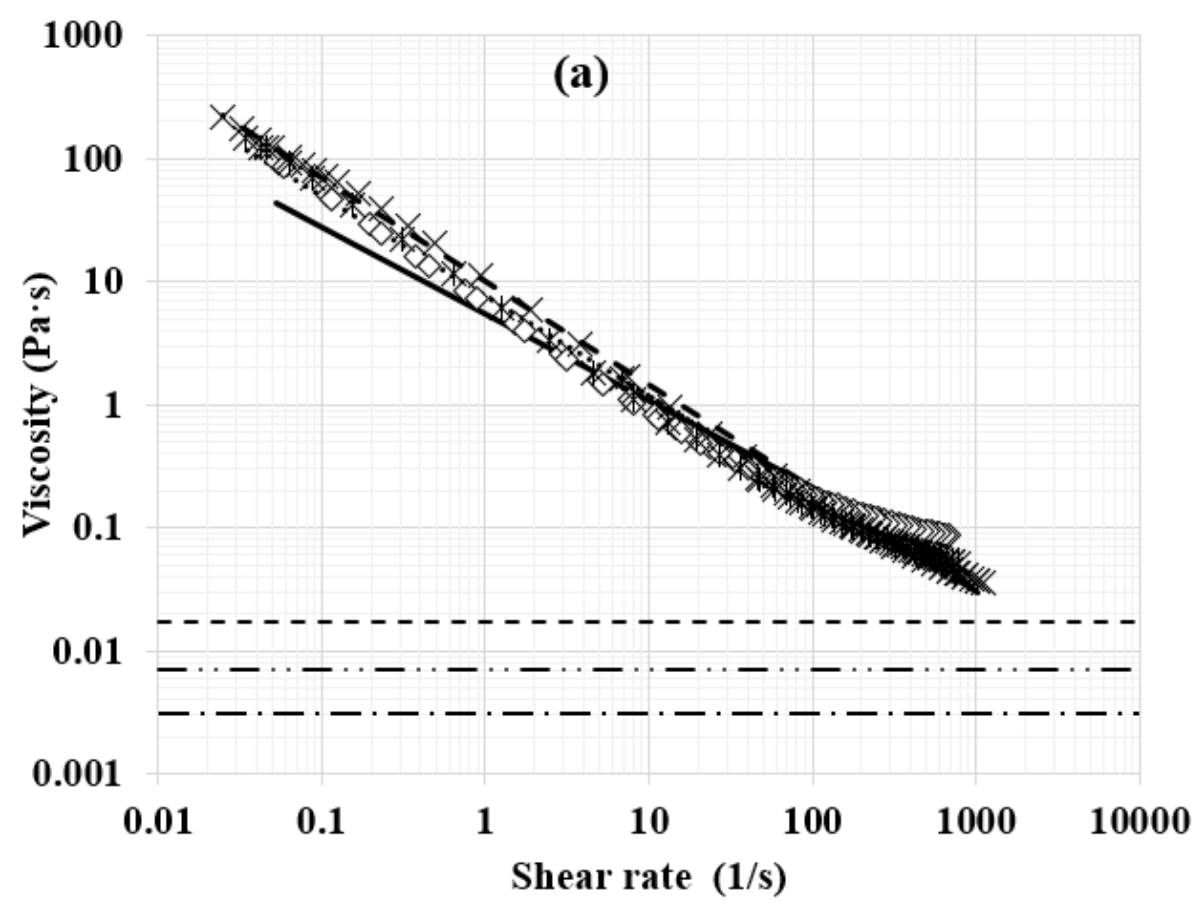




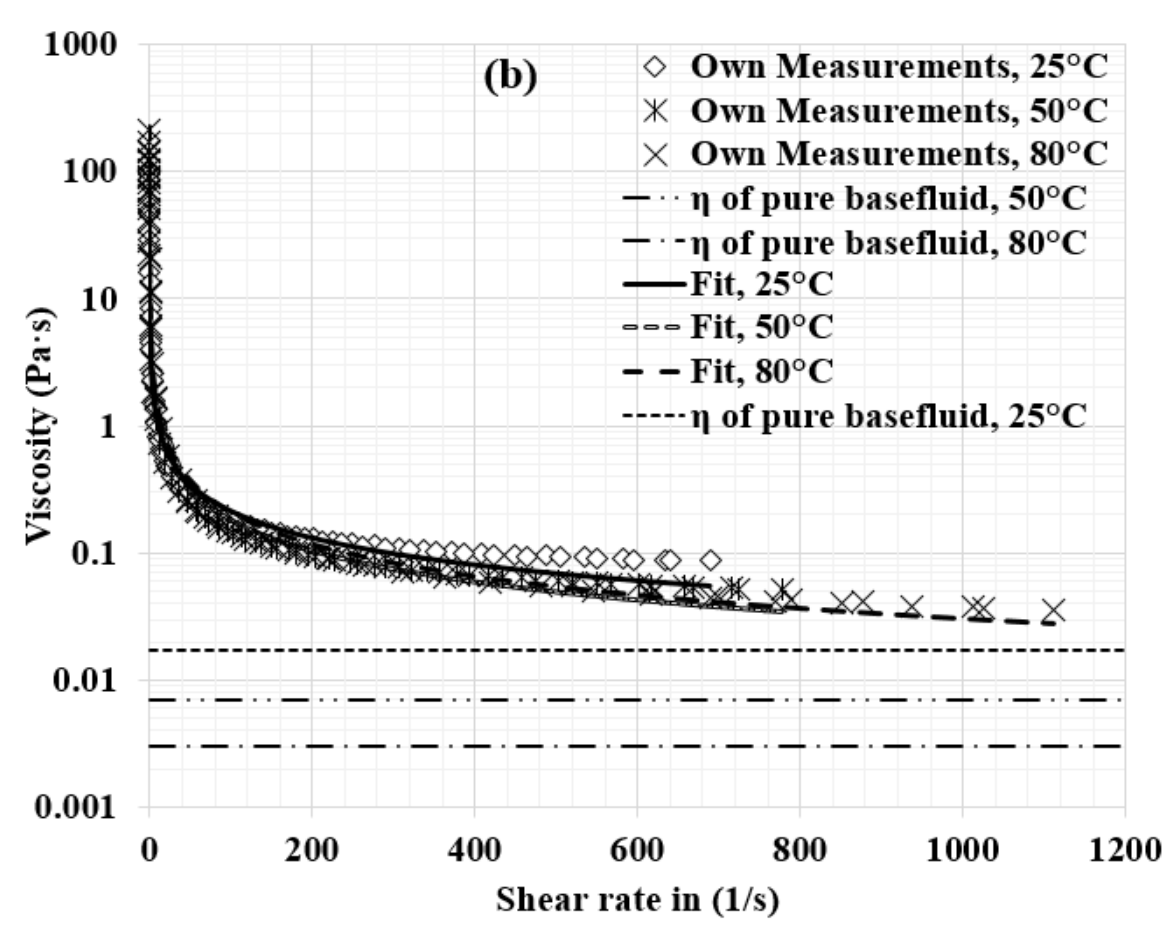

367 Figure 15 Measured viscosities of CuO-ethylene glycol nanofluids with $\phi=15 \%$ and the 368 viscosities of pure ethylene glycol at different temperatures, as a function of the shear rate vs. 369 least square fit (Eq. 10) (a) logarithmically (b) linearly scaled abscissa.

\subsection{Analysis of experimental viscosity data}

First, the hysteresis effect in the measurements of a nanofluid is addressed. This effect has been observed for example by Nguyen et al., when nanofluids are heated above a "critical" temperature. Somewhat lower viscosities of $\mathrm{Al}_{2} \mathrm{O}_{3}$-water and $\mathrm{CuO}$-water nanofluids were measured in the heating phase than in the subsequent cooling phase [51,52]. Hysteresis effects can also be seen in the measurements presented in this paper for increasing and decreasing shear rates, especially at elevated temperatures and higher shear rates. At decreasing shear rates, the viscosity is measured to be lower than at increasing shear rates. As measurements were conducted isothermally, the effect mentioned by Nguyen et al. cannot explain our findings. A possible explanation for this effect is agglomeration. At high shear rates, agglomerates are destroyed leading to better dispersion and thus leading to a decreased viscosity (see especially Figure 13). 
384 Another remarkable behavior is the combination of shear thinning and shear 385 thickening behavior that can be observed in several measurements.

The measurements confirm the expected rheological behavior of a suspension 387 that is described in the literature and comprehensively summarized by Barnes [7]. 388 As it was mentioned before, nanofluids are classified as colloidal suspensions of 389 nanoparticles in base fluids. He states that, with increasing shear rate, particles will begin to align in layers, which leads to a decrease of viscosity (shear thinning), which can last for several magnitudes of shear rates. This can actually be confirmed by most of the measurements shown above. At some point of shear rate, the transition is complete, no more alignment will occur and Newtonian behavior will be observed. The presence of such a Newtonian plateau can also be seen in the current measurements. At higher shear rates the layering is destroyed because of turbulence, and the particles will distribute randomly which results in an increase of viscosity. Such shear thickening behavior could be identified in many of our measurements. It can be concluded that if measurements are conducted at appropriate shear rates, nanofluids will show Newtonian, shear thinning or shear thickening behavior as well. Brown et al. [53] believed that all suspensions are supposed to exhibit shear thickening behavior under appropriate conditions. On the basis of experiments, they concluded that yield stress, which 403 is the shear stress at the starting value of shear rate from zero, directly determines 404 the advent of shear thickening region, as an increase of yield stress pushes the 405 onset of shear thickening to higher values of shear rate. The yield stress also depends on various parameters such as volume fraction of particles, particles size,

407 particle shape, surfactant and etc. which were mentioned by Brown et al.[53] as 408 well as by Barnes [7]. Brown et al. [53] also suggested a correlation to show the 409 interplay between yield stress, shear thinning and shear thickening behavior as 410 follows: 


$$
\tau_{\mathrm{m}}=\tau_{\mathrm{HB}}\left(\dot{\gamma}_{m}\right)+\frac{\varepsilon}{2(1-\varepsilon)}\left(\tau_{\mathrm{HB}}\left(\dot{\gamma}_{m}\right)+\tau_{\mathrm{y}}\right)
$$

411 where $\tau_{\mathrm{m}}$ indicates the lower boundary of the shear thickening region that takes 412 place at the shear rate of $\dot{\gamma}_{m}$ according to a minimum viscosity. $\varepsilon$ is a model 413 parameter, $\tau_{\mathrm{HB}}$ and $\tau_{\mathrm{y}}$ are shear thinning stress and yield stress, respectively. 414 Wagner and Brady [54] also conducted a study to explain the shear thickening 415 phenomena from a more practical point of view. They believe that all suspensions 416 have a common behavior as a function of the shear rate as shown qualitively in 417 Figure 16. In an equilibrium state the inter-particle forces including electrostatics 418 and van-der-Waals forces are stronger than hydrodynamic interactions, so that 419 the particles distribute randomly and the resistance to flow is rather high. By 420 increasing the shear rate, the nanoparticles rearrange in parallel line in flow which 421 lowers the viscosity and the suspension exhibit the shear thinning behavior. With 422 more increase of shear rate the hydrodynamic interactions dominate over the 423 inter-particle forces that drive Brownian motions and severe hydrodynamic 424 coupling between particles result in creation of hydro-clusters which are the 425 apparent features of shear thickening state.

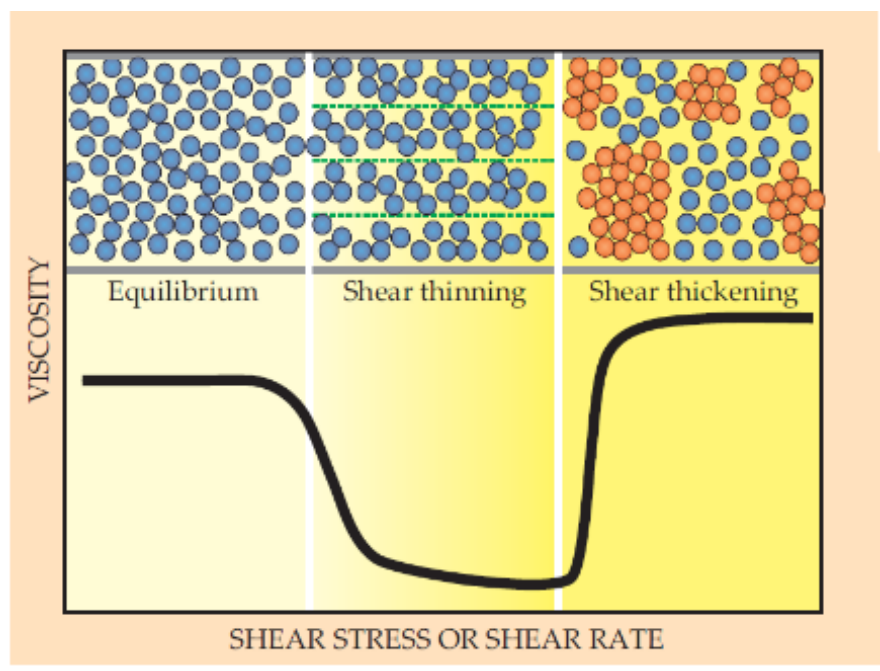



concentrates on the simulation of viscosity of suspensions, considering the influence of Brownian motion and hydrodynamic effects. The simulation results, 431 that are based on prior investigations by Brady, Phung and others, are shown in 432 Figure 17 [56]. Without elaborating on Stokesian dynamics or the hard sphere 433 model, it can be seen that Brownian viscosity $\eta_{B}$ decreases at low Peclet numbers 434 (Pe), whereas the hydrodynamic viscosity $\eta_{H}$ increases with the Peclet number. 435 The two effects result in a local minimum of viscosity. The Peclet number is 436 defined as

$$
\mathrm{Pe}=6 \pi \eta a^{3} \dot{\gamma} /\left(k_{\mathrm{B}} T\right)
$$

with the Boltzmann constant $k_{B}$ and the particle radius $a$ and can be seen as the ratio of Brownian and flow time scales.

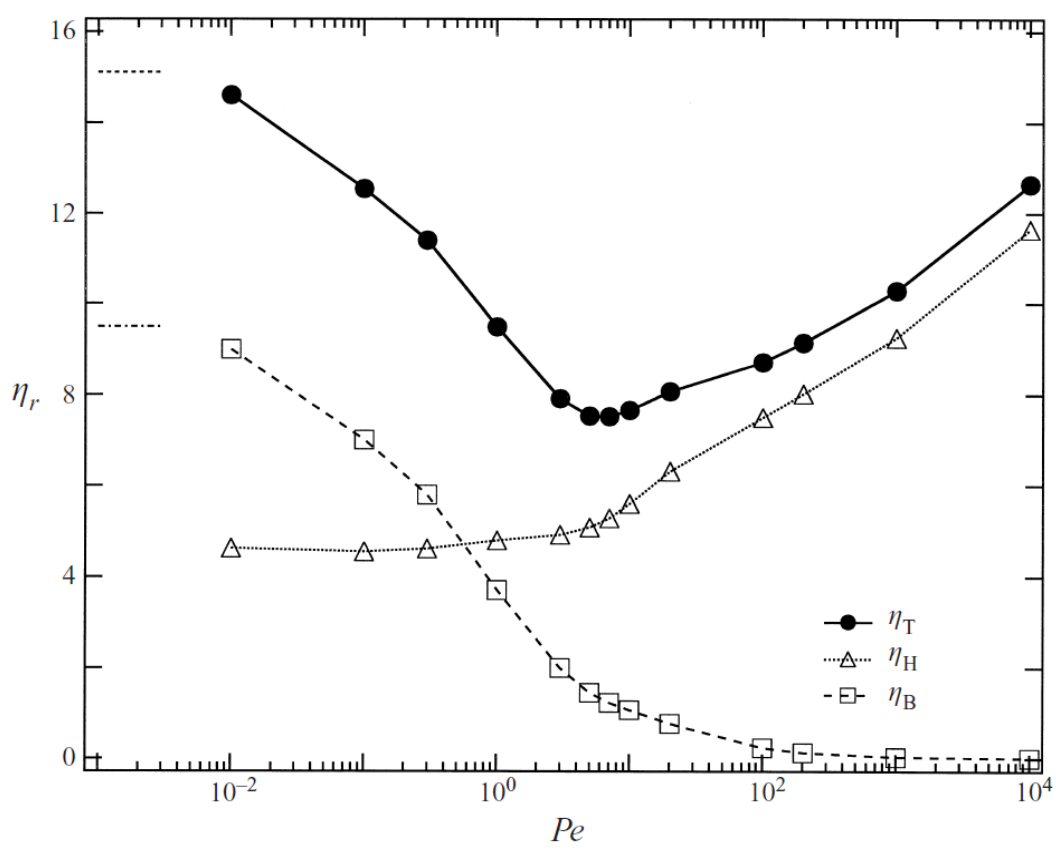

Figure 17 Reduced viscosity as a function of increasing Peclet Number. Horizontal lines on the left describe the viscosity limits for $\mathrm{Pe} \rightarrow 0$. The Brownian contribution $\eta_{B}$ causes shear thinning at low Peclet numbers, whereas hydrodynamic effects $\eta_{\mathrm{H}}$ induce shear thickening for Peclet number Pe > 10 [55] 
445 The shear rate at which viscosity increases is called critical shear rate by 446 Barnes [7] which is shown in Figure 18.

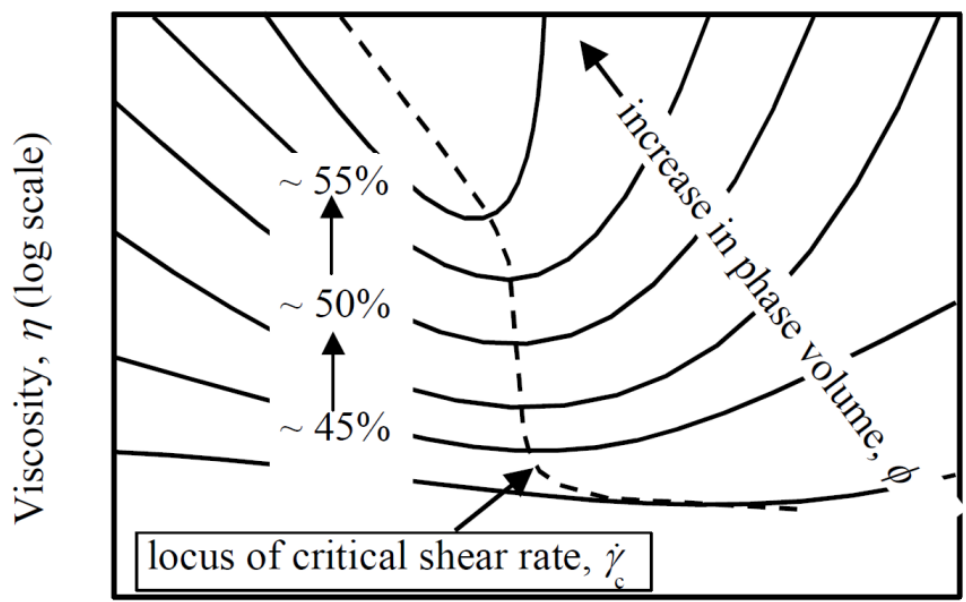

Shear rate, $\dot{\gamma}$ (log scale)

Figure 18 The critical shear rate decreases for increasing phase volume [23]

449 The description of shear dependent viscosity by Foss and Brady [55] and Barnes 450 [7] was given for volume fractions of about $\phi=0.3$ to 0.5 , i.e. for considerably 451 higher particle concentrations than it was dealt with in this paper. A locally strong 452 increase of particle fraction due to agglomerates might however explain the 453 findings. Chen et al. [26] describe that aggregation effects can reduce the usual 454 limit for the onset of shear thinning behavior at $\phi \approx 0.2$ below $\phi=0.1$. Figure 19 455 shows the reduced viscosity of current measurement plotted against the Peclet 456 number, as described by Wager and Brady [54] and Foss and Brady [55]. Note 457 that the onset of shear thickening is observed at about $\mathrm{Pe} \approx 0.1 \ldots 10$, i.e. at about 458 the same order of magnitude for Pe as found in [54,55]. It must be considered 459 that the Peclet number is sensitive to the particle size. Changing the particle 460 diameter for $\mathrm{Al}_{2} \mathrm{O}_{3}$ to e.g. $130 \mathrm{~nm}$ moves the onset of shear thickening to $\mathrm{Pe} \approx 1$. 461 This sensitivity should be considered when discussing the results. 


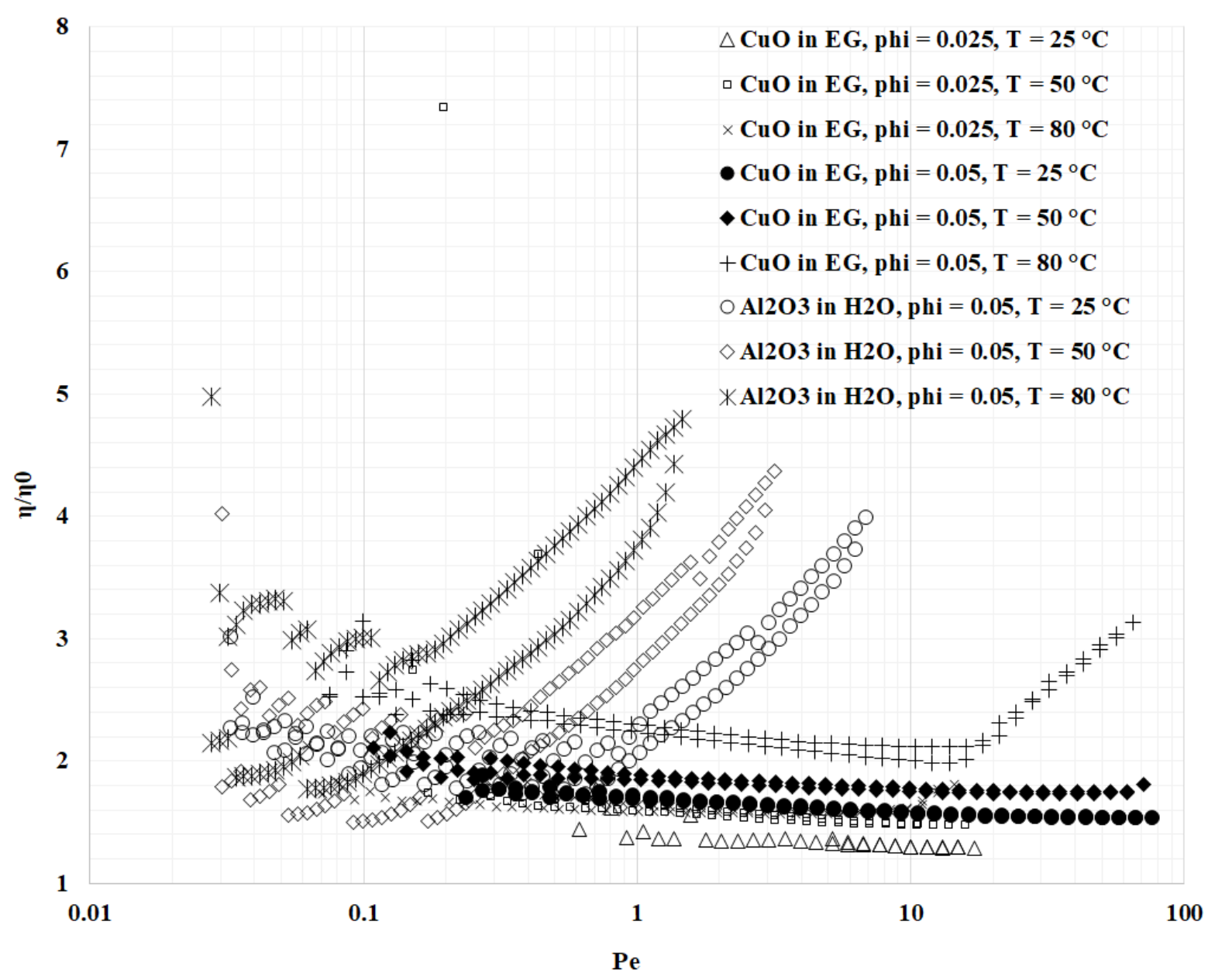

463 Figure 19 Reduced viscosity plotted over Peclet number shows that onset of shear thickening lies in the same order of magnitude as found by Foss and Brady [55].

465 From the explanation and theories that were referred to above from different 466 research groups, it can be concluded that shear thickening is part of the common 467 behavior of suspensions when shear rates increase beyond the critical point. 468 However, this point is dependent on the effective parameters like volume fraction 469 of particles, particles size, particles shape, surfactant etc.

\section{Conclusion}

471 The present work has focused on the experimental data on the rheological 472 behavior of different types of nanofluids consisting of $\mathrm{Al}_{2} \mathrm{O}_{3}, \mathrm{SiO}_{2}$ or $\mathrm{CuO}$ 473 particles in water as well as in ethylene glycol under a wide range of shear rate. 
474 By increasing the shear rate in the measurements, all three rheological classes of 475 shear thinning, Newtonian and shear thickening were observed. The explanation 476 of these phenomena can most probably be found in the arrangement of particles. 477 The particles are distributed randomly at very low shear rates, but as the shear 478 rates increase the particles rearrange themselves in a two dimensional layer, 479 which decreases the efficient viscosity of the nanofluids. At higher shear rates, a 480 transition from the mentioned aligned arrangement to a random three dimensional 481 form occurs that leads to the increase in viscosity. So, according to the obtained 482 results and the mentioned discussion, it can be concluded that both shear thinning 483 as well as shear thickening are parts of the common rheological behavior of 484 nanofluids. Yet, this behavior can occur outside of the shear rate range which was 485 investigated, so that nanofluids seem to be of Newtonian or shear thinning nature 486 only. The findings are, however, crucial for research about correlations 487 addressing nanofluids viscosity. Hysteresis effect is also another interesting 488 phenomena which maybe a result of nanoparticles agglomeration, when shear 489 rates are increased and then decreased. Moreover, in order to thoroughly 490 investigate this phenomena, it is strongly recommended to measure viscosity in 491 both directions, from lower shear rate to higher and vice versa.

492 Data availability

493 The datasets generated during and/or analysed during the current study are 494 available from the corresponding author on reasonable request.

\section{Acknowledgement}

496 This is a post-peer-review, pre-copyedit version of an article published in International Journal of 497 Thermophysics. The final authenticated version is available online at:

498 https://doi.org/10.1007/s10765-019-2508-2

499 


\section{References}

501 1. Pinto, R. V., Fiorelli, F. A. S. Review of the mechanisms responsible for heat 502 transfer enhancement using nanofluids,Applied Thermal Engineering, 2016, 108,

503 720-739.

504 2. Eggers, J.; Kabelac, S. Radiative Properties of a Nanofluid Mixture, J. Heat Transfer $505 \quad$ Conference, Kyoto 2014, 15, 5712-5725.

506 3. Lapotko, D. Plasmonic nanoparticle-generated photothermal bubbles and their 507

508 biomedical applications. J. Nanomedicine 2009, 4, 813-845.

509

510

511

5. Treopia, C.; Yarin, A. L.; Foss, J. F. Springer of Experimental Fluid Mechanics,

512 Springer, 2007.

513 6. Viswanath, D.S.; Prasad, D. H. L.; Dutt, N.V. K.; Rani, K.Y. Viscosity of liquids, Theory, Estimation, Experiment, and Data; Springer: Netherlamd, 2007.

515 7. Barnes, H.A. A handbook of elementary rheology; Institute of Non-Newtonian Fluid Mechanics: University of Wales, 2000.

517

8. $\quad$ Kirkwood, J.G.; Buff, F.P.; Green, H.S. The statistical mechanical theory of transport 518 processes. iii. the coefficients of shear and bulk viscosity of liquids. J. Chemical Physics 1949, 17(10), 988-994.

520

9. Kirkwood, J.G. the statistical mechanical theory of irreversible processes. J. Nuovo Cimento Supply 1949, 6(2), 233-236.

522

10. Born, M.; Green, H.S. A General Kinetic Theory of Liquids; Cambridge Uni. Press: London, 1949.

524

11. Quiñones-Cisneros, S.E.; Deiters, U.K. Generalization of the Friction Theory for 525 Viscosity Modeling. J. Physics Chemistry B 2006, 110, 12820-12834.

12. Quiñones Cisneros, S.E.; Zéberg-Mikkelsen, C.K.; Stenby, E.H. The Friction Theory 527 (f-theory) for Viscosity Modeling. J. FLuid Phase Equilibria 2000, 169, 249-276.

528 13. Brush, S.G. Theories of liquid viscosity. Chemical Reviews 1962, 62, 513-548.

529 14. Eyring, H.; Hirschfelder, J.O. The theory of liquid state. J. physics Chemistry 1937, 4, 530 249-257.

15. Eyring, H. Viscosity, plasticity and diffusion are examples of absolute reaction rates. J. Chemical Physics 1936, 4(4), 283-291. 
533

534

535

536

537

538

539

540

541

542

543

544

545

546

547

548

549

550

551

552

553

554

555

556

557

558

559

560

561

562

563

564

565

566

16. Collins, F.C. Activation energy of the Eyring theory of liquid viscosity and diffusion. J. physics Chemistry 1957, 26(2), 398-400.

17. De Guzman, J. Relation between fluidity and heat of fusion. J. Anales Soc. Espan. Fia.Y. Quim 1913, 11, 353-362.

18. Qun-Fang, L.; Yu-Chen, H.; Rui-Sen, L. Correlation of viscosities of pure liquids in a wide temperature range. J. FLuid Phase Equilibria 1997, 140(1-2), 221-231.

19. Lima, F.W. The viscosity of binary liquid mixtures. J. physics Chemistry 1952, 56, 1052-1052.

20. Tamura, M.; Kurata, M. Viscosity of binary liquid mixtures. J. Bulletin of the Chemical Society of Japan 1952, 25, 32.

21. Hind, R.K.; Mclaughlin, E.; Ubbelohde, U.R. Structure and viscosity of liquids, Camhore+pyrene mixtures. J. Transactions of the Faraday Society 1960, 56, 328-330.

22. Einstein, A. Eine neue Bestimmung der Moleküldimensionen. J. Annalen der Physik 1906, 324(2), 289-306.

23. Einstein, A. Berichtigung zu meiner Arbeit: „Eine neue Bestimmung der Moleküldimensionen. J. Annalen der Physik 1911, 339(3), 591-592.

24. Chen, H.; Ding, Y.; Tan, C. Rheological behavior of nanofluids. New Journal of Physics 2007, 9(367), 1-24.

25. Batchelor, G.K. The effect of Brownian motion on the bulk stress in a suspension of spherical particles. J. Fluid Mechanics 1977, 83, 97.

26. Chen, H.; Ding, A.; Lapkin, A. Rheological behavior of nanofluids containing tube / rod-like nanoparticles. J. Powder Technology 2009, 194, 132-141.

27. Khanafer, K.; Vafai, K. A critical synthesis of thermophysical characteristics of nanofluids. J. Heat and Mass Transfer 2011, 57, 582-594.

28. Mahbubul, L.; Saidur, R.; Amalina, M. Latest developments on the viscosity of nanofluids. J. Heat and Mass Transfer 2012, 55, 874-885.

29. Sundar, L.S.; Sharma, K. V.; Naik, M. T; Singh, M. K. Empirical and theoretical correlations on viscosity of nanofluids: A review. J. Renewable and Sustainable Energy Reviews 2013, 25, 670-686.

30. P.C.Mishra, P. C.; Mukherhjee, S.; Nayak, S. K.; Panda, A. A brief review on viscosity of nanofluid. International Nano Letter 2014. 4(4), 109-120.

31. Prasher, R.; Mukherjee, S.; Nayak, S.K.; Panda, A. Measurements of nanofluid viscosity and its implications for thermal applications. J. Applied Physics Letters 2006, 89(13), 109-120. 
32. Chandrasekar, M.; Suresh, S.; Bose, A.C. Experimental investigations and theoretical determination of thermal conductivity and viscosity of $\mathrm{Al}_{2} \mathrm{O}_{3} /$ water nanofluid. $\mathrm{J}$. Experimental Thermal and Fluid Science 2010, 34, 210-216.

33. Anoop, K.B.; Kabelac, S.; Sundararajan, T.; Das, D. K. Rheological and flow characteristics of nanofluids: Influence of electroviscous effects and particle agglomeration. J. Applied Physics 2009. 106(3), 43909.

34. Yang, Y.; Oztekin, A.; Neti, S.; Mohapatra, S. Particle agglomeration and properties of nanofluids. J. of Nanoparticle Research 2012, 14, 852.

35. Buschmann, M.H. Thermal conductivity and heat transfer of ceramic nanofluids. International Journal of Thermal Sciences 2012, 162, 19-28.

36. Venerus, D.C.; Buongiorno, J.; Christianson, R. Viscosity measurements on colloidal dispersions (nanofluids) for heat transfer applications. J. Applied Rheology 2010, 20(4), 44582.

37. W. Tseng,; Wu, C.H. Sedimentation, rheology and particle-packing structure of aqueous $\mathrm{Al}_{2} \mathrm{O}_{3}$ suspensions. J. Ceramics International 2003. 29(7), 821-828.

38. Tseng, W.J.; Wu, C.H. Aggregiation, rheology and electrophoretic packing structure of aqueous $\mathrm{Al}_{2} \mathrm{O}_{3}$ nanoparticle suspensions. J. Acta Materialia 2000, 50, 3757-3766.

39. Tseng, W.J.; Tzeng, F. Effect of ammonium polyacrylate on dispersion and rheology of aqueous ITO nanoparticle colloids. J. Colloid and Surfaces A 2006, 276(1-3), 3439.

40. Davies, J.; Binner, J. G. P. The role of ammonium polyacrylate in dispersing concentrated alumina suspensions. J. the Europian Ceramic Society 2000, 20(10), 1539-1553.

41. Tseng, W.J.; Lin, C.L. Effects of dispersants on rheological behaviour of $\mathrm{BaTiO}_{3}$ powders in ethanol-isopropanol mixtures. J. Materials Chemistry and Physics 2003, 80(1), 232-238.

42. Tseng W. J.; Chen. C-N. Dispersion and rheology of nickel nanoparticle inks. J. Materials Science 2006, 41(4), 1213-1219.

43. Tseng, W.J.; Li, S.Y. Rheology of colloidal BaTiO3 suspension with ammoniumpolyacrylate as a dispersant. J. Materials Science and Engineering: A 2002, 333(1), 314-319.

44. Aladag, B.; Halelfadl, S.; Doner, N.; Mare, T.; Duret, S.; Estelle, P. Experimental investigations of the viscosity of nanofluids at low temperatures. J. Applied Energy 2012, 97, 876-880. 
601

602

603

604

605

606

607

608

609

610

611

612

613

614

615

616

617

618

619

620

621

622

623

624

625

626

627

628

629

630

631

632

45. Hong, R.Y.; Pan, T. T.; Han, Y. P.; Li, H. Z.; Ding, J.; Han, S. Magneticfield synthesis of $\mathrm{Fe}_{3} \mathrm{O}_{4}$ nanoparticle used as a precursor of ferrofluids. J. Magnetism and Magnetic Materials 2007, 310(1), 37-47.

46. Hong, R.Y.; Etemad, S. Gh. ; Bagheri, R. ; Thibault, J. Rheological properties of waterbased $\mathrm{Fe}_{3} \mathrm{O}_{4}$ ferrofluids. J. Chemical Engineering Science 2007, 62(21), 5912-5924.

47. Garg, J.; Poudel, B.; Chiesa, M.; Gordon, J. B.; Ma, J. J.; Wang, J. B.; Ren, Z. F.; Kang, Y. T.; Ohtani, H.; Nanda, J.; McKinley, G. H.; Chen. G. Enhanced thermal conductivity and viscosity of copper nanoparticles in ethylene glycol nanofluid. J. Applied Physics 2008, 103, 074301.

48. Hojjat, M.; Etemad, S. Gh.; Bagheri, R.; Thibault, J. Rheological characteristics of nonNewtonian nanofluids: Experimental investigation. J. International Communications in Heat and Mass Transfer 2011, 38, 144-148.

49. Namburu, P.; Kulkarni, D. P.; Misra, D.; Das, D. K. Viscosity of copper oxide nanoparticles dispersed in ethylene glycol and water mixture. J. Experimental Thermal and Fluid Science 2007, 32(2), 397-402.

50. Kole, M.; Dey, T.K. Thermal conductivity and viscosity of $\mathrm{Al}_{2} \mathrm{O}_{3}$ nanofluid based on car engine coolant. J. Physics D 2010, 43, 315501.

51. Nguyen, C.; Desgranges, F.; Roy, G.; Galanis, N.; Mare, T.; Boucher, S.; Mintsa, H. A. Temperature and particle-size dependent viscosity data for water-based nanofluids Hysteresis phenomenon. J. Heat and Fluid Flow 2007, 28(6), 1492-1506.

52. Nguyen, C.; Kulkarni, D. P.; Misra, D.; Das, D. K. Viscosity data for $\mathrm{Al}_{2} \mathrm{O}_{3}$-water nanofluid-hysteresis: is heat transfer enhancement using nanofluids reliable? J. Thermal Sciences 2008, 47, 103-111.

53. Brown, E.; Forman, N. A. ; Orellana, C. S.; Zhang, H.; Maynor, B. W.; Betts, D. E.; DeSimone, J. M.; Jaeger, H. M. Generality of shear thickening in dense suspensions. J. Nature Materials 2010, 9, 220-224.

54. Wagner, N.J.; Brady, J.F.Generality of shear thickening in dense suspensions. J. Physics Today 2009, 62(10), 27-32.

55. Foss, D.R.; Brady, J.F. Structure, diffusion and rheology of Brownian suspensions by Stokesian Dynamics simulation. J. Fluid Mechanics, 2000, 407, 167-200.

56. Phung, T.N.; Brady, J.F.; Bossis, G. Stokesian Dynamics simulation of Brownian suspensions. J. Fluid Mech. 1996, 313,181-207. 